\title{
Inorganic Polymer Cement from Fe-Silicate Glasses: Varying the Activating Solution to Glass Ratio
}

\author{
Lieven Machiels • Lukas Arnout • Peter Tom Jones • \\ Bart Blanpain · Yiannis Pontikes
}

Received: 13 October 2013/Accepted: 13 February 2014

(C) Springer Science+Business Media Dordrecht 2014

\begin{abstract}
Large volumes of Fe-silicate glasses-slagsare produced as residues of metal production and waste treatment processes. It would be interesting if these materials could become an alternative group of precursors for the synthesis of inorganic polymer (IP) cements. This paper investigates the polymerisation of Fe-silicate glasses of composition (in wt\%) $\mathrm{SiO}_{2}: 40 ; \mathrm{FeO}: 30 ; \mathrm{CaO}: 15 ; \mathrm{Al}_{2} \mathrm{O}_{3}$ : 8 and an activating solution of composition (in wt $\%$ ) $\mathrm{Na}_{2} \mathrm{O}$ : 15; $\mathrm{SiO}_{2}: 13 ; \mathrm{H}_{2} \mathrm{O}: 72$. The mass ratio of the activating solution to the glass (L/S) was varied from 0.3 to 1.0 and the effect on the IP chemistry, microstructure and properties was investigated. Despite the high $\mathrm{Fe}$ and low $\mathrm{Al}$ contents of the glass, an IP cement could be synthesised, resistant to water dissolution and delivering mortars of compressive strength $>52 \mathrm{MPa}$ after 28 days curing at room temperature when using a L/S ratio of 0.45 . Lowering the ratio from 1.00 to 0.45 results in a significant improvement in compressive strength, a lower porosity and when immersed in water, $\mathrm{Na}$ dissolution is decreased and water $\mathrm{pH}$ is lower. Microstructural investigation indicates that when the amount of activating solution is decreased, the degree of glass dissolution is lower resulting in less IP formation and a more homogeneous IP chemistry. Compared to higher L/S ratios, the IP mortar has a more densely packed microstructure of partially dissolved glass and sand
\end{abstract}

L. Machiels $(\bowtie) \cdot$ L. Arnout · P. T. Jones · B. Blanpain ·

Y. Pontikes

High Temperature Processes and Industrial Ecology, Department

of Metallurgy and Materials Engineering, KU Leuven,

Kasteelpark Arenberg 44, 3001 Leuven, Belgium

e-mail: lieven.machiels@gmail.com aggregates bound by the IP matrix. At lower L/S ratios, the formation of micro scale shrinkage cracks in the IP matrix is strongly reduced, while at higher L/S ratios, shrinkage cracking is more pronounced and individual micro-cracks connect to form more pronounced large scale cracks. At a $\mathrm{L} / \mathrm{S}$ ratio of 0.45 , the IP cement is composed of $90 \mathrm{wt} \% \mathrm{Fe}-$ silicate glass and only $10 \mathrm{wt} \% \mathrm{Na}$-silicate (\% of powder mix) and it is indicated that this percentage can still be reduced. As $90 \mathrm{wt} \%$ of this IP cement is composed of an industrial residue and as curing is performed at ambient temperatures, its production is expected to have important ecological and economic benefits.

Keywords Inorganic polymer - Geopolymer · Ironsilicate glass · Non-ferrous slags · Glass dissolution · Sodium silicate $\cdot$ Sodium hydroxide

\section{Introduction}

Geopolymers are covalently bonded chains or networks, most commonly alkali-alumino-silicates, which are X-ray amorphous at ambient and medium temperatures and $\mathrm{X}$-ray crystalline at temperatures $>500{ }^{\circ} \mathrm{C}$ [1]. Geopolymers are synthesised from $\mathrm{Si}-\mathrm{Al}$ rich, commonly amorphous precursor materials, such as calcined clays, volcanic glasses and metallurgical slags and ashes in combination with an alkaline activating solution, which is commonly a mixture of $(\mathrm{Na}, \mathrm{K})$ hydroxides and soluble silicates [1]. Although non-aluminosilicate structure types, such as phosphates and iron-aluminosilicates have been included in geopolymer terminology, other authors refer to the more general term inorganic polymers for these materials and this term will also be used in this paper (abbreviation IP, [2]). 
While the understanding of the chemistry, structure and properties of aluminosilicate IPs is substantial, this does not hold true for IPs of differing compositions. An alternative group of IPs is derived from iron silicate precursors, containing only limited amounts of aluminium. Potential natural iron silicate IP precursors are ultramafic igneous rocks, such as peridotites and dunites or calcined ironphyllosilicates. The polymerisation of volcanic ashes containing $\sim 13$ wt $\% \quad \mathrm{Fe}_{2} \mathrm{O}_{3}$ has been studied recently [3]. However, studies on polymerisation of iron silicates have typically focussed on slags produced by the non-ferrous industry. In this case, the production of IP could be an interesting, high added value solution for the high volumes of slag produced by this industry. Examples of IPs from Ferich precursors include materials synthesised from lead slag ( $>27$ wt \% FeO [5]), FeNi slag ( $>35$ wt\% FeO [6-9]), copper slag ( $>50$ wt $\% \mathrm{FeO}$ [10]) and $\mathrm{Fe}-\mathrm{Al}$ slag [4]. Among others, these Fe-silicate glasses share the following common characteristics: (a) they are semi-vitreous, (b) the iron oxidation state is mostly bivalent, and (c) they have an $\mathrm{Al}_{2} \mathrm{O}_{3}$ level $<10 \mathrm{wt} \%$ [4]. Other sources of Fe-silicate precursors are the slags produced as a result of the thermal treatment of municipal solid waste. Certain technologies involve melting of the inorganic residues and rapid cooling, forming a glass (vitreous) precursor for downstream applications [e.g. 11, 12].

The present article studies the synthesis of IPs from $\mathrm{Fe}-$ $\mathrm{Si}$-rich and Al-poor glasses with the Fe content being in the lower range of $\mathrm{Fe}$-silicate slag compositions (in wt $\% \mathrm{SiO}_{2}$ : 40; $\mathrm{FeO}: 30$; $\mathrm{CaO}: 15 ; \mathrm{Al}_{2} \mathrm{O}_{3}: 8$ ). The first objective of this paper is to explore the possibility of synthesising IPs from these glasses and to describe their chemistry, microstructure and physical and mechanical properties. The second objective is to investigate the influence of using varying amounts of activating solution on the IP properties. The relation between activating solution composition and IP properties, such as compressive strength and water solubility have been extensively investigated for aluminosilicate IP precursors [1, 13-16]. Focus in these works is on the molar ratios of $\mathrm{Na}_{2} \mathrm{O} / \mathrm{SiO}_{2}$ and $\mathrm{H}_{2} \mathrm{O} / \mathrm{Na}_{2} \mathrm{O}$ of the activating solution. In the field of Fe-silicate glasses, Komnitsas et al. investigated the influence of the activating solution composition on the compressive strength of IP synthesised from Fe-Ni slag [7]. For both the $\mathrm{NaOH}$ molarity and the percentage of $\mathrm{Na}$-silicate solution an optimum was obtained, while compressive strength values were lower if concentrations were reduced or raised. While in the abovementioned approach $\mathrm{Na}_{2} \mathrm{O} / \mathrm{SiO}_{2} / \mathrm{H}_{2} \mathrm{O}$ ratios were varied and optimised, another approach is used in this paper. A single activating solution is used, with the $\mathrm{Na}_{2} \mathrm{O}$ / $\mathrm{SiO}_{2} / \mathrm{H}_{2} \mathrm{O}$ ratios fixed, and the total amount of activating solution used, i.e. the activating solution to glass ratio (L/S ratio), varies per sample.

\section{Materials and Methods}

\section{Materials}

Fe-silicate glass was synthesised on laboratory scale by melting and water quenching a mixture of synthetic metal oxide powders. The following glass chemistry was synthesised (in wt \%): $\mathrm{SiO}_{2}=40 ; \mathrm{FeO}=30 ; \mathrm{CaO}=15$; $\mathrm{Al}_{2} \mathrm{O}_{3}=8 ; \mathrm{MgO}=2 ; \mathrm{K}_{2} \mathrm{O}=1.5 ; \mathrm{TiO}_{2}: 1 ; \mathrm{Na}_{2} \mathrm{O}: 0.5$; $\mathrm{ZnO}, \mathrm{Cr}_{2} \mathrm{O}_{3}, \mathrm{CuO}, \mathrm{PbO}, \mathrm{NiO}: 0.4$. The powders were molten at $1,450{ }^{\circ} \mathrm{C}$ in a bottom loading furnace using a $\mathrm{Pt}$ crucible under an atmosphere rich in Ar. Samples were maintained for $30 \mathrm{~min}$ at $1,450{ }^{\circ} \mathrm{C}$ before pouring the melt in water to obtain a glassy material with limited crystalline phases $(<5 \mathrm{wt} \%)$. To assess whether the desired chemistry and glass content were obtained after melting and water quenching, the glass was analysed using quantitative X-ray powder diffraction analysis (QXRPD, D500, Siemens) and quantitative micro-analysis using wavelength-dispersive X-ray spectroscopy (WDS, Jeol JXA-8530F EPMA, 10 nA and $15 \mathrm{keV}$, obsidian as standard). For QXRPD analysis, $10 \mathrm{wt} \%$ of analytical grade crystalline $\mathrm{ZnO}$ was added as internal standard and the slag-standard mixture was milled in a McCrone Micronizing mill ${ }^{\circledR}$ using ethanol as grinding agent and a grinding time of $7.5 \mathrm{~min}$, to obtain a $\mathrm{d}_{50}$ particle size lower than $10 \mu \mathrm{m}$. X-ray diffraction patterns were obtained over a $2 \theta$ range of $5-70^{\circ}$ using $\mathrm{CuK} \alpha$ radiation of $40 \mathrm{kV}$ and $40 \mathrm{~mA}$, a $0.02^{\circ}$ step size and step time of $2 \mathrm{~s}$. Quantitative results were obtained adopting the Rietveld method using the "Topas ${ }^{\circledR}$ Academic" software [17-19]. A fundamental parameter approach was used, meaning that instrumental contributions to the peak shapes were calculated directly and the standard parameters (cell parameters, crystallite size, lattice strain, diffraction optical effects and background) were refined [20]. EPMA analyses were performed on the unreacted core of glass particles in the IP monoliths, analyses of $100 \pm 5 \mathrm{wt} \%$ were accepted, ZAF corrections were applied and results were normalised. $\mathrm{Na}$ was measured first using $10 \mathrm{~s}$ counting time to avoid migration. For the preparation of the IP, the Fe-silicate glass was milled in a Fritsch ${ }^{\circledR}$ disk mill to a grain size finer than $500 \mu \mathrm{m}$, subsequently in a Retsch ${ }^{\circledR}$ centrifugal mill, using a $250 \mu \mathrm{m}$ sieve and final grinding was done in a Retsch $^{\circledR}$ ball mill with grinding times of 20 and 60 min to obtain two different grain sizes with a $\mathrm{d}_{50}$ particle size of 50 and $3 \mu \mathrm{m}$ respectively. The grain size distribution was analysed using wet laser scattering analysis (Malvern Mastersizer S).

IP mortars were prepared using CEN standard sand (EN 196-1 conforming to ISO 679-referred to as "sand" in this text [21]) and the two milled glass fractions. To approach a closest possible particle packing of the glass particles, particle size distribution curves were introduced 
Table 1 Composition of IP mixtures in wt $\%$

\begin{tabular}{lllllcc}
\hline wt\% & L/S & Glass & $\begin{array}{l}\text { NaOH (dry } \\
\text { weight) }\end{array}$ & $\begin{array}{l}\text { Na-Silicate } \\
\text { (dry weight) }\end{array}$ & $\begin{array}{l}\mathrm{H}_{2} \mathrm{O} \\
\text { (total) }\end{array}$ & Sand \\
\hline GP1 & 0.30 & 23.26 & 1.00 & 1.21 & 4.77 & 69.77 \\
GP2 & 0.45 & 22.47 & 1.44 & 1.75 & 6.92 & 67.42 \\
GP3 & 0.60 & 21.74 & 1.86 & 2.25 & 8.93 & 65.22 \\
GP4 & 1.00 & 20.00 & 2.86 & 3.46 & 13.7 & 59.99 \\
\hline
\end{tabular}

$\mathrm{L} / \mathrm{S}$ ratio is calculated as activating solution $(\mathrm{NaOH}+\mathrm{Na}$-silicate $+\mathrm{H}_{2} \mathrm{O}$ ) to glass ratio

Sand $=$ Standard CEN sand

in the Emma Mix analyser software to calculate the optimal mixing ratios [22]. Mixing proportions of the glass fractions were varied to fit a modified Andreassen curve ( $q$ value 0.37 ) representing closest possible particle packing in the $0.1-100 \mu \mathrm{m}$ size range. This resulted in the selection of a mixing ratio of $1: 1.5$ of the 3 and $50 \mu \mathrm{m}$ glass fractions. Glass to CEN sand mass ratio was maintained 1:3 in all mortars. The resulting mixture with ratios of glass $(3 \mu \mathrm{m})$ :glass $(50 \mu \mathrm{m})$ :CEN sand of 1:1.5:7.5 was used for all mortars prepared. As activating solution, a 50:50 weight ratio $\mathrm{NaOH} 10 \mathrm{M}-\mathrm{Na}$-silicate solution was used (mixture composition in wt $\% \mathrm{Na}_{2} \mathrm{O}: 15 ; \mathrm{SiO}_{2}: 13 ; \mathrm{H}_{2} \mathrm{O}: 72$ ). The $\mathrm{NaOH} 10 \mathrm{M}$ solution was prepared by dissolving analytical grade $\mathrm{NaOH}$ pellets overnight in distilled water and keeping it in sealed plastic containers. As Na-silicate solution, an analytical grade commercial solution was used $\left(\mathrm{SiO}_{2} 25.5-28.5 \%, \mathrm{Na}_{2} \mathrm{O} 7.5-8.5 \%\right.$, density $1.35-$ $1.38 \mathrm{~g} / \mathrm{mL})$.

\section{Inorganic Polymer Mixture Compositions}

The IP mixture compositions used in this work are indicated in Table 1. The activating solution composition was fixed (water $+\mathrm{NaOH}+\mathrm{Na}$-silicate) while the activating solution to glass ratio (further abbreviated as $\mathrm{L} / \mathrm{S}$ ) was varied from 0.3 to 1.0 .

Knowing the amounts and composition of the glass and of the activating solution, the mixture composition can be determined. This is the IP composition that would be formed if all glass is dissolved, if all glass and activating solution participate in the reaction and if reaction is homogeneous throughout the sample. The mixture compositions used in this work are given in Table 2. In reality, the calculated composition will differ from the actual IP composition, as typically only the outer rim of the glass will be dissolved and participate in the reaction [1]. However, it is interesting to compare mixture molar ratios with the composition of the IP formed (determined by microchemical analysis) and with mixing ratios reported in literature. The mixing ratios of samples GP1-GP4 are given in Table 3. For aluminosilicate IP, the mixing ratios of
Table 2 Mixture compositions for the different L/S ratios, calculated on water free basis

\begin{tabular}{lrrrr}
\hline $\mathrm{wt} \%$ & $\mathrm{GP} 1$ & $\mathrm{GP} 2$ & $\mathrm{GP} 3$ & $\mathrm{GP} 4$ \\
\hline $\mathrm{Si}$ & 18.5 & 18.6 & 18.7 & 19.0 \\
$\mathrm{Na}$ & 3.5 & 4.8 & 6.1 & 9.0 \\
$\mathrm{Al}$ & 4.2 & 4.1 & 3.9 & 3.6 \\
$\mathrm{Ca}$ & 9.4 & 9.0 & 8.7 & 7.9 \\
$\mathrm{Fe}$ & 24.7 & 23.8 & 22.9 & 20.9 \\
$\mathrm{~K}$ & 1.0 & 0.9 & 0.9 & 0.8 \\
$\mathrm{Mg}$ & 1.0 & 1.0 & 0.9 & 0.8 \\
\hline
\end{tabular}

$\mathrm{Na}_{2} \mathrm{O} / \mathrm{SiO}_{2}, \mathrm{Na}_{2} \mathrm{O} / \mathrm{Al}_{2} \mathrm{O}_{3}, \mathrm{SiO}_{2} / \mathrm{Al}_{2} \mathrm{O}_{3}$ and $\mathrm{Na}_{2} \mathrm{O} / \mathrm{H}_{2} \mathrm{O}$ have been related to properties, such as the compressive strength $[13,23]$. The ratios that should be applied to achieve an optimal compressive strength in aluminosilicate IP mixtures are given for comparison in Table 3 $[13,23]$. For Fe-silicate IP, optimal ratios are not well defined yet and therefore the ranges used for IP synthesis by Lemougna et al. [3] are given for comparison in Table 3.

In aluminosilicate IP mixtures, ideally the amount of $\mathrm{Na}$ in the mixture is equal to the amount of negative charges required by $\mathrm{Si}^{4+} \Leftrightarrow \mathrm{Al}^{3+}$ substitution in the IP network [1]. The $\mathrm{Na}_{2} \mathrm{O} / \mathrm{Al}_{2} \mathrm{O}_{3}$ mixing ratio should thus be determined from the $\mathrm{Al}$ content of the precursor system and assuming that only part of the precursor dissolves, by the amount of $\mathrm{Al}$ which is dissolved and which is incorporated in the IP network. Systems with higher Al content thus require higher contents of $\mathrm{Na}$ from the activating solution. Additionally, the $\mathrm{NaOH}$ content also determines the degree of precursor dissolution, as dissolution occurs through hydrolysis of $\mathrm{Si}-\mathrm{O}-\mathrm{Si}$ bonds to form $\mathrm{Si}-\mathrm{O}-\mathrm{Na}$ and $\mathrm{Si}-\mathrm{O}-\mathrm{H}$ [14]. Excess $\mathrm{Na}$, which is not required for charge balancing in the IP structure, will form other phases such as Nacarbonates or will break $\mathrm{Si}-\mathrm{O}-\mathrm{Si}$ bonds and thus lead to a lower degree of polymerisation or less extensive IP network formation [24]. For Fe-silicate precursors, it is more difficult to determine the ideal $\mathrm{Na}$ content of the mixes, as Fe can also be incorporated in the IP network [3], while the Al content is low. When looking at the molar ratios reported in Table 3, it is noted that $\left(\mathrm{Na}_{2} \mathrm{O}+\mathrm{K}_{2} \mathrm{O}\right) / \mathrm{SiO}_{2}$ and $\mathrm{H}_{2} \mathrm{O} /\left(\mathrm{K}_{2} \mathrm{O}+\mathrm{Na}_{2} \mathrm{O}\right)$ ratio lie in the same ranges as the ratio reported by Davidovits [13], but as the $\mathrm{Al}$ content of the glasses is much lower, $\mathrm{SiO}_{2} / \mathrm{Al}_{2} \mathrm{O}_{3}$ and $\left(\mathrm{Na}_{2} \mathrm{O}+\mathrm{K}_{2} \mathrm{O}\right) /$ $\mathrm{Al}_{2} \mathrm{O}_{3}$ mixing ratios are higher. However, as $\mathrm{Fe}$ also most probably forms part of the IP phases, optimal ratios shouldn't necessarily be the same as for aluminosilicate IPs and therefore the $\mathrm{SiO}_{2} /\left(\mathrm{Al}_{2} \mathrm{O}_{3}+\mathrm{Fe}_{2} \mathrm{O}_{3}\right)$ and $\left(\mathrm{Na}_{2}\right.$ $\left.\mathrm{O}+\mathrm{K}_{2} \mathrm{O}\right) /\left(\mathrm{Al}_{2} \mathrm{O}_{3}+\mathrm{Fe}_{2} \mathrm{O}_{3}\right)$ ratios are also reported. When comparing these with the ratios reported by Lemougna [3] for IP produced from Fe-rich glasses, it is observed that only mixture GP1 lies within the range 
Table 3 Mixture compositions for the different L/S ratios, calculated on water free basis

\begin{tabular}{lccccc}
\hline Molar ratios & $\mathrm{GP} 1$ & $\mathrm{GP} 2$ & $\mathrm{GP3}$ & $\mathrm{GP} 4$ & $\begin{array}{l}\text { Davidovits [11], } \\
\text { Barbosa et al. [39] }\end{array}$ \\
\hline$\left(\mathrm{Na}_{2} \mathrm{O}+\mathrm{K}_{2} \mathrm{O}\right) / \mathrm{SiO}_{2}$ & 0.12 & 0.16 & 0.2 & 0.28 & $0.2-0.28$ \\
et al. [38]
\end{tabular}

Ratios of Davidovits [13] Barbosa et al. [23] and Lemougna et al. [3] are given for comparison

reported by the authors, while mixtures GP2-GP4 have higher $\left(\mathrm{Na}_{2} \mathrm{O}+\mathrm{K}_{2} \mathrm{O}\right) /\left(\mathrm{Al}_{2} \mathrm{O}_{3}+\mathrm{Fe}_{2} \mathrm{O}_{3}\right)$ ratios.

\section{Inorganic Polymer Synthesis}

When the samples of varying L/S are compared, it can be seen that increasing the amount of activating solution results only in a minor increase in the total Si content of the mix, as the amount of Si added is rather small compared to the amount of $\mathrm{Si}$ present in the glass. Na on the contrary almost triples and $\mathrm{H}_{2} \mathrm{O}$ doubles when comparing samples of lowest and highest L/S ratio. All other elements, which are delivered only from dissolution of the glass, are progressively diluted in the mix composition when more activating solution is added. Although the $\mathrm{H}_{2} \mathrm{O} / \mathrm{Na}_{2} \mathrm{O}$ ratio of the activating solution is the same for the different $\mathrm{L} / \mathrm{S}$, the $\mathrm{H}_{2} \mathrm{O} /\left(\mathrm{Na}_{2} \mathrm{O}+\mathrm{K}_{2} \mathrm{O}\right)$ ratio slightly increases towards higher $\mathrm{L} / \mathrm{S}$ ratio, as limited amounts of $\mathrm{Na}$ and $\mathrm{K}$ are also delivered by the glass.

The large difference in activating solution content of the mixtures resulted in a strong difference in fluidity of the samples of different L/S ratio. During the synthesis of IP mortars, the sample of highest L/S ratio (1.0, GP4) was a "liquid" mixture, which could be easily poured into a mould, while the mixtures of intermediate L/S ratio of 0.45 (GP2) and 0.6 (GP3) had a more "plastic" behaviour. The mixture with the lowest L/S ratio of 0.3 (GP1) was a "dry" mixture, which could be pressed in a mould without excess liquid leaving the mould. When no sand was included, sample GP1 behaved as plastic, whereas all other samples were liquid. During preliminary experiments, samples were mixed mechanically, using a Dispermat $\mathrm{CN}$ mixer. This is an efficient procedure for "liquid" samples, even with high viscosities, which could be easily mixed, but "dry samples", such as samples GP1 and GP2 were projected to the containers walls rather than mixed. Fluidity could be enhanced by adding water to the mixtures, but this would bias the objective of this paper to maintain a constant activating solution composition. To exclude any influence of a different behaviour during mechanical mixing on the IP microstructure and properties, it was chosen to premix glass - sand mixtures dry for $24 \mathrm{~h}$ in a laboratory Turbula mixer and to subsequently gently manually mix the powders with the activating solution for $1 \mathrm{~min}$. In this way complete mixing of the two glass fractions and the sand was ensured, all samples were prepared identically and the effects of different behaviour during mechanical mixing were minimised. For all L/S ratio, $200 \mathrm{~g}$ of IP mortar was prepared, which was divided over six $2.5 \times 2.5 \times 2.0 \mathrm{~cm}^{3}$ plastic moulds. Samples GP2 and GP3 were introduced with a spatula in a mould and sample GP4 was poured. To compact the samples, they were tapped 10 times manually. Due to its dry appearance, sample GP1 was difficult to compact and was, therefore, pressed in a $3.3 \mathrm{~cm}$ diameter steel mould at $100 \mathrm{kN}$ and, subsequently, demoulded. IP pastes without CEN sand were prepared in the same way as the mortars. All samples were wrapped in plastic foil and cured for 28 days at ambient conditions. After 7 days, all samples were unwrapped to observe their appearance. All samples had hardened, although sample GP1 had an earthy appearance, with sand grains coming off easily, and samples GP3 and GP4 still had a liquid layer on the upper side of the monolith. All liquids dried up after 14 days of curing.

\section{Inorganic Polymer Characterisation Techniques}

After 28 days, samples were unwrapped and polished for compressive strength testing. Uniaxial compressive strength measurements were performed after 28 and 100 days curing time on the polished $2.5 \times 2.5 \times 2.0 \mathrm{~cm}$ samples or on the round $3.3 \times 2.0 \mathrm{~cm}$ diameter pressed samples using a Schenck Trebel apparatus with head displacement of $1 \mathrm{~mm} / \mathrm{s}$. All subsequent analyses were done after 100 days of curing. To measure the water solubility of the IP phase, the monoliths were crushed in a mortar and pestle to $<500 \mu \mathrm{m}$ and subsequently in a Retsch centrifugal mill using a sieve of $80 \mu \mathrm{m}$, resulting in a $\mathrm{d}_{50}$ of $20 \mu \mathrm{m}$. 
Table 4 Quantitative mineralogical analysis of the glass used as IP precursor by quantitative $\mathrm{X}$-ray diffraction analysis

\begin{tabular}{llllll}
\hline wt\% & Magnetite & Quartz & Periclase & Calcite & Glass \\
\hline 4.1 & 0.3 & 1.8 & 0.3 & 93.5 \\
\hline
\end{tabular}

Powdered samples were immersed in distilled water at a ratio of $100 \mathrm{~g} / \mathrm{l}$ and were shaken in a glass jar on a shaking table for $24 \mathrm{~h}$. Directly afterwards, samples were filtered using filtration paper of $0.45 \mu \mathrm{m}$ pore size and the $\mathrm{Si}, \mathrm{Al}$, $\mathrm{Na}, \mathrm{Fe}, \mathrm{K}, \mathrm{Mg}$ content of the solution was measured using ICP-OES analysis. The resistance to water immersion of the IP monoliths was tested by hanging the entire monoliths in a sealed container filled with $200 \mathrm{~mL}$ distilled water for 7 days. For the study of the bond structure in the IP phases, Attenuated Total Reflectance-Fourier-Transform Infrared Spectroscopy, ATR-FTIR, was employed in the 4,000-650 $\mathrm{cm}^{-1}$ range (ATR-FTIR, Perkin Elmer, Spectrum 100). For FTIR analysis, monoliths were crushed using a mortar and pestle to $<500 \mu \mathrm{m}$ and subsequently with a McCrone Micronizing mill ${ }^{\circledR}$ using ethanol as grinding agent and a grinding time of $5 \mathrm{~min}$. QXRD analyses of the pastes were performed using the methodology described above. The microstructure of the samples was studied on carbon coated fracture surfaces and impregnated polished sections using scanning electron microscopy with secondary electron (SE) and backscattered electron (BSE) images (SEM XL30, Philips, $15 \mathrm{keV}$ ). To avoid changes in the samples during polished section preparation, the samples were impregnated under vacuum with a low viscosity resin before polishing (Epo thin, Buehler). Water absorption tests were performed on the monoliths in accordance to ISO 10545:3 [25]. Pore size distribution was determined by mercury intrusion porosimetry (Micromeritics AutoPore IV). To determine the degree of glass dissolution and IP phase formation, the total area of undissolved glass and of the IP phase were quantified applying image analysis of SEM-BSE images of $350 \times$ magnification using the Image Pro Plus software. Ten images were taken at different locations in each sample, to cover possible heterogeneity through the sample and to provide some statistical significance. Microchemical analyses were performed with EPMA analysis, using the conditions as described above.

\section{Results}

\section{Glass Precursor Characterisation}

The quantitative mineralogical analysis of the Fe-silicate glass is shown in Table 4. The melting and quenching
Table 5 Major element chemical analysis of Fe-silicate glass by EPMA-WDS measurement

\begin{tabular}{lcrrrrrrr}
\hline wt\% & $\mathrm{SiO}_{2}$ & $\mathrm{Al}_{2} \mathrm{O}_{3}$ & $\mathrm{FeO}$ & $\mathrm{CaO}$ & $\mathrm{Na}_{2} \mathrm{O}$ & $\mathrm{MgO}$ & $\mathrm{K}_{2} \mathrm{O}$ & Total \\
\hline Average & 38.7 & 8.2 & 28.9 & 13.6 & 2.0 & 2.0 & 1.5 & 100.4 \\
Min & 35.9 & 6.0 & 26.8 & 12.4 & 1.6 & 1.9 & 1.2 & 95.5 \\
Max & 41.0 & 10.1 & 32.3 & 14.9 & 3.0 & 2.1 & 1.7 & 104.6 \\
\hline
\end{tabular}

resulted in a glass content of $93.5 \mathrm{wt} \%$. Small amounts of quartz, periclase and calcite are present, as well as considerable amounts of magnetite, which is formed in the relatively oxidative conditions of the air-argon atmosphere.

The microchemical analysis of the glass is shown in Table 5. Element percentages are expressed in oxides, $\mathrm{Fe}$ is expressed as $\mathrm{FeO}$, but could be present as both $\mathrm{Fe}(+\mathrm{II})$ and $\mathrm{Fe}$ (+III). Chemical analyses correspond well to the composition of the powder mix used for glass synthesis given above. The Fe content in the glass is somewhat lower than the bulk $\mathrm{Fe}$ content as part of the $\mathrm{Fe}$ is present in magnetite, resulting in a depletion of $\mathrm{Fe}$ in the glass. When glass particles are observed on BSE images, it can be seen that some particles contain dendritic magnetite crystals, while these are absent in others, explaining the range in glass compositions.

Proof of Concept: Inorganic Polymer Synthesis from Fe-Silicate Glass

To have a first indication whether IP synthesis was successful, FTIR analysis and quantitative X-ray diffraction analyses were performed on the samples and the IP monoliths were subjected to compressive strength and water immersion tests.

\section{FTIR Analysis}

The FTIR patterns of the powdered Fe-silicate glass and pastes of GP1-GP4 are shown in Fig. 1. The Fe-silicate glass shows a broad peak at $895 \mathrm{~cm}^{-1}$, which is attributed to the $\mathrm{Si}-\mathrm{O}-\mathrm{T}$ (T: $\mathrm{Al}$ or $\mathrm{Si}$ ) bond asymmetric stretching vibrations [26, 27] which changes into a double peak at $879 \mathrm{~cm}^{-1}$ and $915-924 \mathrm{~cm}^{-1}$ after polymerisation. The lower peak at $879 \mathrm{~cm}^{-1}$ is attributed to the addition of $\mathrm{Na}-$ silicate [10] and is more prominent towards higher $\mathrm{L} / \mathrm{S}$ ratios. The shift from $895 \mathrm{~cm}^{-1}$ to higher values is attributed to the formation of a new reaction product which suggests that IP formation has indeed taken place [28]. The shift is lower for sample GP1 $\left(915 \mathrm{~cm}^{-2}\right)$ and GP4 $\left(919 \mathrm{~cm}^{-2}\right)$ compared to samples GP2 $\left(923 \mathrm{~cm}^{-2}\right)$ and GP3 $\left(924 \mathrm{~cm}^{-2}\right)$, possibly indicating the presence of a higher amount of nonbridging oxygens, and thus a lower degree of polymerisation in samples GP1 and GP4 [29]. 


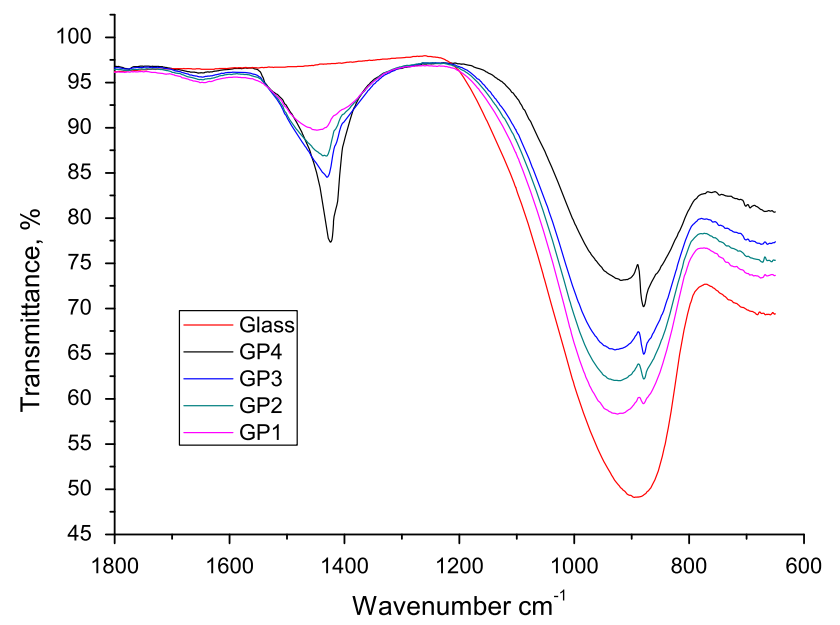

Fig. 1 FTIR analysis of the glass and IP pastes

The new band with a peak at $1,444 \mathrm{~cm}^{-1}$ is due to stretching vibrations of $\mathrm{O}-\mathrm{C}-\mathrm{O}$ and indicates the presence of carbonates, whereas the bands around $1650 \mathrm{~cm}^{-1}$ are ascribed to stretching $(-\mathrm{OH})$ vibrations of bound water molecules [7, 8]. The band at $1,444 \mathrm{~cm}^{-1}$ is also more prominent towards higher L/S ratios, possibly indicating that the amount of carbonates formed is higher towards higher towards higher $\mathrm{L} / \mathrm{S}$ ratios.

\section{Quantitative X-ray Diffraction}

The results of the quantitative mineralogical analysis of the IP pastes are shown in Table 6. The non-polymerised glass analyses are given for the sake of comparison. Newly formed crystalline phases in the IP samples are gaylussite $\left(\mathrm{Na}_{2} \mathrm{Ca}\left(\mathrm{CO}_{3}\right)_{2} \cdot 5\left(\mathrm{H}_{2} \mathrm{O}\right)\right)$ and thermonatrite $\left(\mathrm{Na}_{2} \mathrm{CO}_{3} \cdot \mathrm{H}_{2} \mathrm{O}\right)$. In GP1, a minor amount of calcite is also formed. The formation of carbonates and the fact that more carbonates are formed towards a higher $\mathrm{L} / \mathrm{S}$, as was observed in the FTIR analyses, is confirmed. As no other newly formed crystalline phases are observed, the IP phase is considered as being X-ray amorphous.

\section{Compressive Strength}

The results of the compressive strength analyses are shown in Table 7. All results represent compressive strength of
Table 7 Indicative values for uniaxial compressive strength

\begin{tabular}{llllr}
\hline Unit $(\mathrm{MPa})$ & GP1 & GP2 & GP3 & GP4 \\
\hline 28 days & 14 & 34 & 35 & 15 \\
100 days & 23 & 57 & 53 & 48 \\
28 days $(\mathrm{d} 50: 3 \mu \mathrm{m})[30]$ & 17 & 52 & 19 & 2 \\
\hline
\end{tabular}

The samples studied in the current paper were prepared from a mixture of glass $(3 \mu \mathrm{m})$ :glass $(50 \mu \mathrm{m})$ :sand ratios of 1:1.5:7.5. Previously published data [30], in which a mixture ratio of glass $(3 \mu \mathrm{m})$ :sand of 1:3 was used, are reported for comparison

the dry samples, equilibrated under ambient conditions. Due to limitations in the amount of glass that could be synthesized, no duplicate samples could be made for strength testing and results should thus be considered as indicative. Nonetheless, samples prepared with the same $\mathrm{L} / \mathrm{S}$ but having a smaller particle size of $3 \mu \mathrm{m}$, reported in a previous publication [30, Table 7], indicate a similar trend. The samples from the current publication indicate that: (1) Sample GP1 and GP4 develop the lowest strength, but the strength of GP4 improves considerably towards 100 days. (2) The strength of samples GP2 and GP3 are similar at 28 days and the strength of GP2 is slightly higher compared to GP3 at 100 days (57 and $53 \mathrm{MPa}$ respectively). For finer glass grain size, when comparing to coarser grain size, the following is observed: (1) compressive strength is higher in GP1 and GP2, while it is lower in GP3 and GP4; (2) high strengths are obtained earlier (28 days) in samples GP1 and GP2.

\section{Water Immersion Test}

To test the resistance of the IP monoliths to water immersion, the IP cubes, after 100 days of curing, were hung into a container with distilled water for 1 week. Water immersion did not have any visible effects on the IP monoliths. In a second test, the IP monoliths were crushed and shaken in distilled water for $24 \mathrm{~h}$. The solution composition at the end of this test is given in Table 8. In the upper part of the table, the total amount dissolved is given for the major elements ( $\mathrm{mg} /$ per $\mathrm{kg}$ IP monolith), while in the lower part the ratio of the dissolved amount to the total amount present in the sample (excluding sand) is given. It

Table 6 Quantitative X-ray diffraction results of GP1-GP4 (pastes). Glass analysis is given for comparison

\begin{tabular}{|c|c|c|c|c|c|c|c|}
\hline & Magnetite & Quartz & Periclase & Calcite & Gaylussite & Thermonatrite & Amorphous \\
\hline glass & 4.1 & 0.3 & 1.8 & 0.3 & - & - & 93.5 \\
\hline GP1 & 1.3 & 0.1 & 1.4 & 0.9 & 0.3 & 0.3 & 95.7 \\
\hline GP2 & 1.3 & 0.6 & 1.1 & 0.2 & 3.6 & 1.2 & 92.0 \\
\hline GP3 & 1.4 & 0.3 & 1.0 & 0.1 & 4.0 & 1.0 & 92.3 \\
\hline GP4 & 1.0 & 0.6 & 1.2 & 0.3 & 5.1 & 5.9 & 85.9 \\
\hline
\end{tabular}


Table 8 Dissolution of major elements from the powdered IP monoliths after crushing and $24 \mathrm{~h}$ of shaking in distilled water

\begin{tabular}{|c|c|c|c|c|c|c|c|c|}
\hline & $\mathrm{Al}$ & $\mathrm{Ca}$ & $\mathrm{Fe}$ & $\mathrm{K}$ & $\mathrm{Mg}$ & $\mathrm{Na}$ & $\mathrm{Si}$ & $\mathrm{pH}$ \\
\hline \multicolumn{9}{|c|}{$\mathrm{mg} / \mathrm{kg}$ monolith } \\
\hline GP1 & 4 & 29 & 11 & 360 & 2 & 1668 & 211 & 9.55 \\
\hline GP2 & 3 & 20 & 10 & 302 & 1 & 2158 & 213 & 10.00 \\
\hline GP3 & 2 & 41 & 7 & 348 & 0 & 2564 & 390 & 10.33 \\
\hline GP4 & 3 & 54 & 10 & 339 & 1 & 2969 & 497 & 10.44 \\
\hline \multicolumn{9}{|c|}{$\%$ of element dissolved } \\
\hline GP1 & 0.01 & 0.03 & 0.00 & 3.71 & 0.02 & 5.25 & 0.11 & \\
\hline GP2 & 0.01 & 0.02 & 0.00 & 3.21 & 0.01 & 4.88 & 0.11 & \\
\hline GP3 & 0.01 & 0.05 & 0.00 & 3.83 & 0.01 & 4.59 & 0.21 & \\
\hline GP4 & 0.01 & 0.07 & 0.00 & 4.08 & 0.01 & 3.58 & 0.26 & \\
\hline
\end{tabular}

(Curing 100 days, d50: $20 \mu \mathrm{m}, 100 \mathrm{~g} / \mathrm{L}$ ). Expressed in $\mathrm{mg}$ dissolved/ $\mathrm{kg}$ IP monolith (upper part) and \% of element dissolved (lower part)

can be observed that dissolution is negligible for all elements except silica ( $<0.3 \%$ dissolved) and alkalis (up to $4 \%$ of $\mathrm{K}$ and $5 \%$ of $\mathrm{Na}$ are dissolved) and dissolution increases towards higher L/S ratios. The solution $\mathrm{pH}$ also increases towards higher $\mathrm{L} / \mathrm{S}$ ratios. As the dissolved amount of silica is limited, it can be concluded that the IP phase formed has limited water solubility. As indicated by Davidovits [1], during polymerisation of the IP network, excess $\mathrm{Na}$ is expelled. The combination of high $\mathrm{Na}$ dissolution and limited $\mathrm{Si}$ dissolution indicates that $\mathrm{Na}$ is not dissolving from the IP phase, but from another, more soluble phase, possibly the Na-carbonate phases encountered in the FTIR and QXRD analyses.

\section{Microstructure and Porosity}

In the previous section it was demonstrated that an IP phase could be synthesised from Fe-silicate glass having low contents of Al. It was also indicated that decreasing the $\mathrm{L} / \mathrm{S}$ ratio from 1.00 to 0.45 resulted in a decreased release of alkalis upon water immersion and an increase in compressive strength of the IP monolith. The aim of the following sections is to obtain a more fundamental understanding of the role of the activating solution by studying the microstructure, porosity and microchemistry of IP monoliths synthesised at different L/S ratios. Figure $2 \mathrm{a}$ shows a representative SEM-BSE image of the monolithic mortar sample GP2 of L/S ratio 0.45 , which delivered the highest compressive strength values. As indicated earlier, only part of the Fe-silicate glass is dissolved in the activating solution, and the undissolved part of the glass aggregates can be observed (white colour). The sand aggregates, composed mainly of quartz, are dark grey in colour and the newly formed IP matrix, which cements the glass and sand particles, can be observed as the interstitial phase. Porosity is composed of shrinkage cracks and round air voids (upper left in Fig. 2a). At higher magnifications ( $>20.000 \mathrm{X}$, Fig. 2b) under SE mode, the morphology of the matrix can be observed, being composed of spherical 50-100 nm size aggregates, a typical morphology which has been recognised also in aluminosilicate IP [31].

When the samples of differing L/S ratios are compared, some important differences can be observed in:

- the degree of dissolution of glass particles and-related to this-the amount of IP matrix formed;

- the distribution and packing of sand aggregates;

- the size, shape and total volume of pores;

- the size and connectivity of cracks in the IP matrix.

\section{Glass Dissolution}

The IP matrix is formed from constituents derived from glass dissolution which combine with $\mathrm{Na}$ and $\mathrm{Si}$ from the activating solution. As indicated in the section "Materials and methods", not all glass dissolves and participates in the reaction. Typically, only small glass particles are dissolved completely, while only the outer rim of larger particles is dissolved. The undissolved part of the glass particles will thus act as aggregates bound by the newly formed IP matrix. In Fig. 3 it can be observed that the ratio of glass to IP phase strongly differs in samples of differing L/S, with an increase in IP phase occurring towards higher L/S ratios. The glass to IP ratio depends on two factors, being (1) the initial glass to activating solution ratio, as additional activating solution will deliver extra $\mathrm{Na}$ and $\mathrm{Si}$ to the system and (2) the degree of glass dissolution. To quantify the difference in undissolved glass to IP ratio between the different samples, image analysis of SEM-BSE images was performed (Table 9). For sample GP2, GP3 and GP4, the total area of remaining glass decreases from 27, to 24 to $17 \%$ respectively (glass + IP phase $=100 \%$ ). When comparing these values with the original percentage of glass in the mixtures, obtained from Table 1, it can be calculated how much of the glass has been dissolved. It has to be indicated that the values obtained are indicative, as no conversion from area to weight percentages has been made. However, comparison between the different samples can still be made. Results indicate that a higher degree of glass dissolution occurs when more activating solution is added, with $76 \%$ of the glass being dissolved in GP2 towards $82 \%$ in GP4.

For sample GP1 the amount of undissolved glass could not be calculated, as pores occurring between glass grains have similar grey values as the IP matrix in the SEM-BSE images and their inclusion in the calculation would overestimate the percentage of IP matrix. However, when looking at Fig. 3a, it is obvious that glass dissolution and IP matrix formation is limited. Glass fragments are angular 


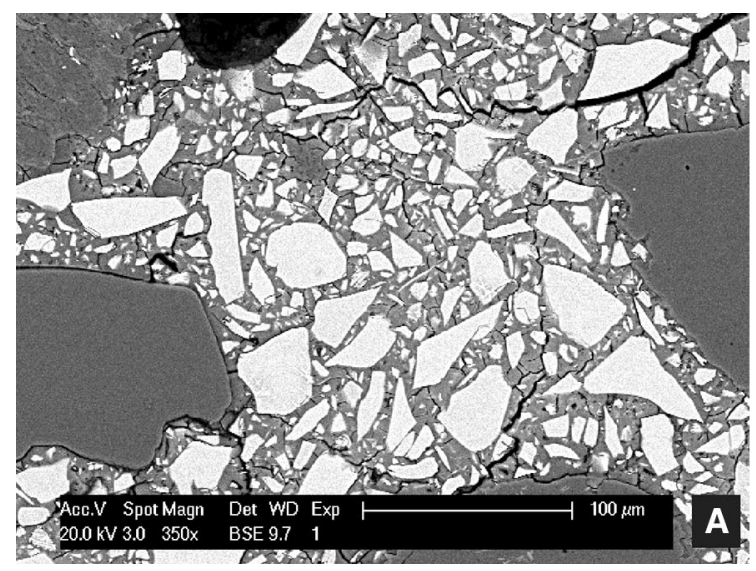

Fig. 2 SEM images of sample GP2, synthesised at an optimal L/S of 0.45. a BSE image (350X) showing detail of the glass-IP matrix. Sand aggregates have a dark grey colour, remaining glass particles are white and the IP matrix is light grey. Glass particles act as small

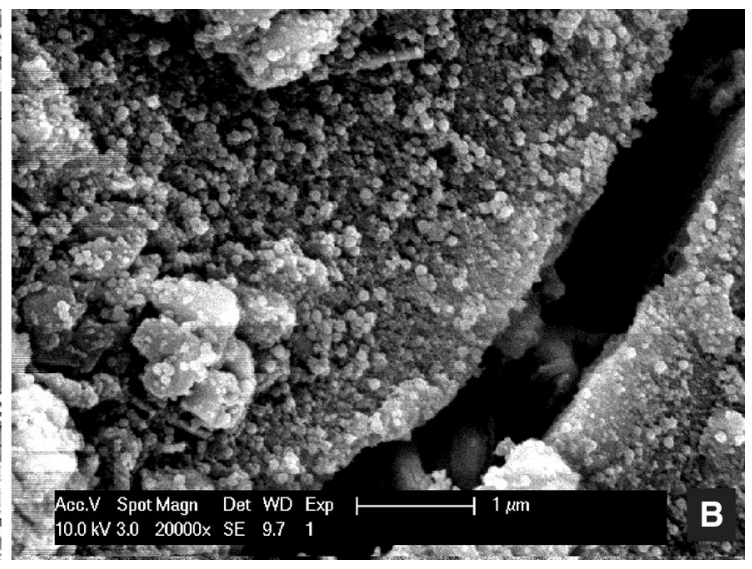

aggregates filling the gaps between larger sand aggregates, as only their rim has been dissolved. Shrinkage cracks are visible in the IP matrix. b SE images (20000x) showing spherical IP aggregates, $50-100 \mathrm{~nm}$ in size
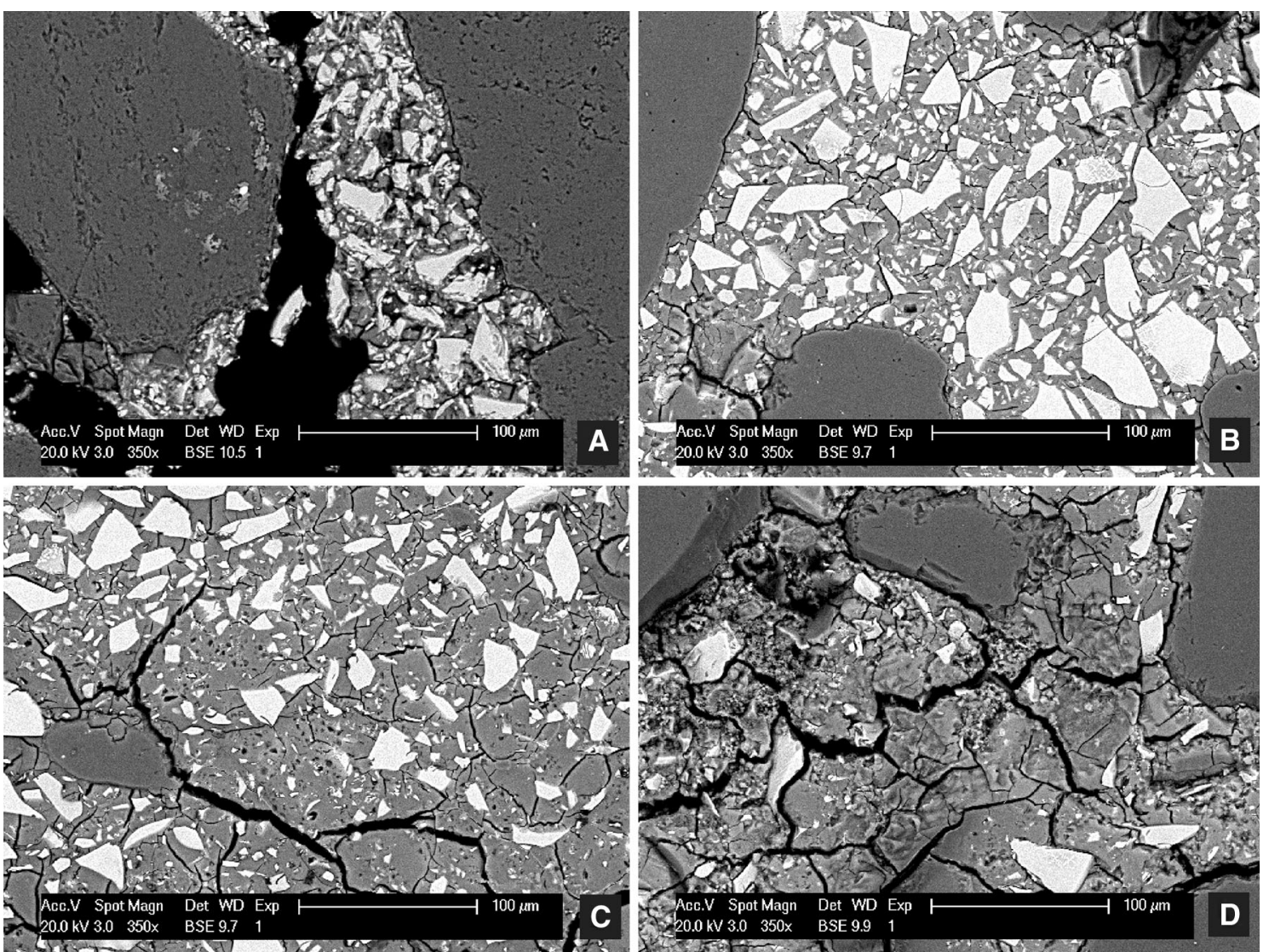

Fig. 3 SEM images indicating increased degree of glass dissolution towards higher L/S ratio. a Sample GP1 (L/S 0.3); b Sample GP2 (L/S 0.45); c Sample GP3 (L/S 0.6); d Sample GP4 (L/S 1.0)

and touch each other at many locations, resulting in a particle supported structure. Additionally, strong differences are observed throughout the sample. This can be explained by the low amount of activating solution, which was insufficient to react with the whole sample, resulting in regions of higher and lower glass dissolution and IP formation. In sample GP2 on the contrary, glass dissolution and IP formation are homogeneous through the sample (Fig. 2a). Edges of glass particles are more rounded compared to sample GP1 and particles are surrounded by the IP 
Table 9 Total area of undissolved glass determined by image analysis of SEM-BSE images. (Glass + IP matrix $=100 \%$ )

\begin{tabular}{llll}
\hline & GP2 & GP3 & GP4 \\
\hline $\begin{array}{l}\text { Remaining glass (\% of area glass + IP } \\
\text { matrix) }\end{array}$ & $27 \pm 5$ & $24 \pm 4$ & $17 \pm 5$ \\
Original \% glass in mixture (wt $\%)$ & 87 & 84 & 75 \\
$\%$ of glass dissolved & 76 & 78 & 82
\end{tabular}

Original $\%$ of glass is calculated from Table 1 (glass/(NaOH $+\mathrm{Na}-$ silicate) on dry basis)

matrix, which fills all interstitial porosity, resulting in a matrix supported system. In sample GP3, glass dissolution and IP matrix formation are more extensive and additionally, large differences are observed throughout the sample. These differences could be partially due to physical segregation of glass particles during mixing or tapping, but the presence of glass particle "ghosts", being dissolved glass particles of which the former presence is indicated by undissolved magnetite crystals and glass impurities, indicates that dissolution rather than physical segregation is responsible for this. The highest degree of glass dissolution can be observed in sample GP4 (Fig. 3d).

\section{Aggregate Particle Packing}

Figure 4 shows SEM-BSE images of the IP samples of varying $\mathrm{L} / \mathrm{S}$ ratio at a lower magnification, which makes it possible to observe the packing of aggregates and the distribution of glass and the IP matrix through the samples. When looking at sample GP2 (Fig. 4b), it can be seen that a good packing has been obtained for sand grains and that the pore space between the sand grains is filled with smaller glass aggregates cemented by the IP matrix. This structure is homogenous through the sample. The microstructure is strongly different in sample GP1 (Fig. 4a), in which glass particles tend to occur clustered together in zones, or alternatively they are aligned around sand grain boundaries, rather than filling the voids between them. This results in a structure supported by sand grains and the occurrence of large pores between the sand grains and zones of clustered glass aggregates, which are bound by the IP matrix. In sample GP3 at some locations the microstructure is similar as in GP2, but in general the distribution of sand aggregates is very heterogeneous throughout the sample. As dissolution of sand aggregates is negligible, this can only be caused by physical segregation of small and large aggregates, which probably occurred during the tapping of the samples directly after casting. At some locations, nearly no sand aggregates are present (Fig. 5c). Figure 4c shows a zone of the sample where only smaller sand aggregates are present. Physical segregation of larger and smaller glass aggregates seems to occur, as can be observed in Fig. 5c. However, this could also be explained by a varying degree of dissolution and IP formation, as explained in the previous paragraph, or by a combination of both processes. As sample GP2 was "plastic" upon moulding, while sample GP3 was still very liquid, this segregation was prevented in sample GP2. In the previous paragraph it was explained that the highest degree of glass dissolution occurred in sample GP4. Although locally the high degree of glass dissolution leads to high amounts of IP matrix formation (Fig. 3d), in general, much less IP matrix is present in the core of the sample, as can be observed when comparing Fig. 4b (GP2) and 4d (GP4). However, as was indicated earlier, extensive bleeding occurred during the preparation of the sample and a liquid layer was still present after 7 days on the upper part of the sample. After 14 days this layer has dried up resulting in IP formation on the top of the sample. In the core of the sample, the extensive dissolution with only limited IP formation resulted in a structure in which dissolution compaction is obvious and in which sand aggregates are touching (Fig. 4d). The system is thus supported by the sand grains rather than the IP matrix, as is the case in samples GP2 and GP3.

\section{Porosity and Cracks}

A large difference in porosity and cracking occurs in the samples of different $\mathrm{L} / \mathrm{S}$ ratios. Different types of pores can be observed in the SEM images. A distinction is made between "large pores" (LP, $>100 \mu \mathrm{m})$, "small pores" (SP, $<100 \mu \mathrm{m}$ and commonly $<5 \mu \mathrm{m}$ ) and cracks (present in all size ranges). Two types of large pores are distinguished, being spherical pores (e.g. Fig. 4b, c) and irregularly shaped pores (Fig. 4a). Small pores are inter-particle pores, occurring between glass fragments, at locations where the intra-particle space has not been filled completely by the IP matrix. Large spherical pores resulted from air entrapped during the mixing and are present in samples which were liquid or plastic during preparation and which were casted. Only in sample GP1 these pores are absent. Irregularly shaped large pores occur between sand grains and are present in samples GP1 and GP4, where they are very common (Fig. 4a, d). As explained previously, in sample GP1, glass aggregates tend to be clustered together, cemented by the IP matrix, or are deposited in layers around sand grains and are not filling the pores between sand aggregates, resulting in a large residual porosity between the sand grains. In sample GP4, high glass dissolution without extensive IP matrix formation in the central part (core) of the sample resulted in a dissolution compaction structure with large irregular pores along sand boundaries.

In all samples, cracks occurred within the IP matrix, but they differ in size, amount and connectivity and these 

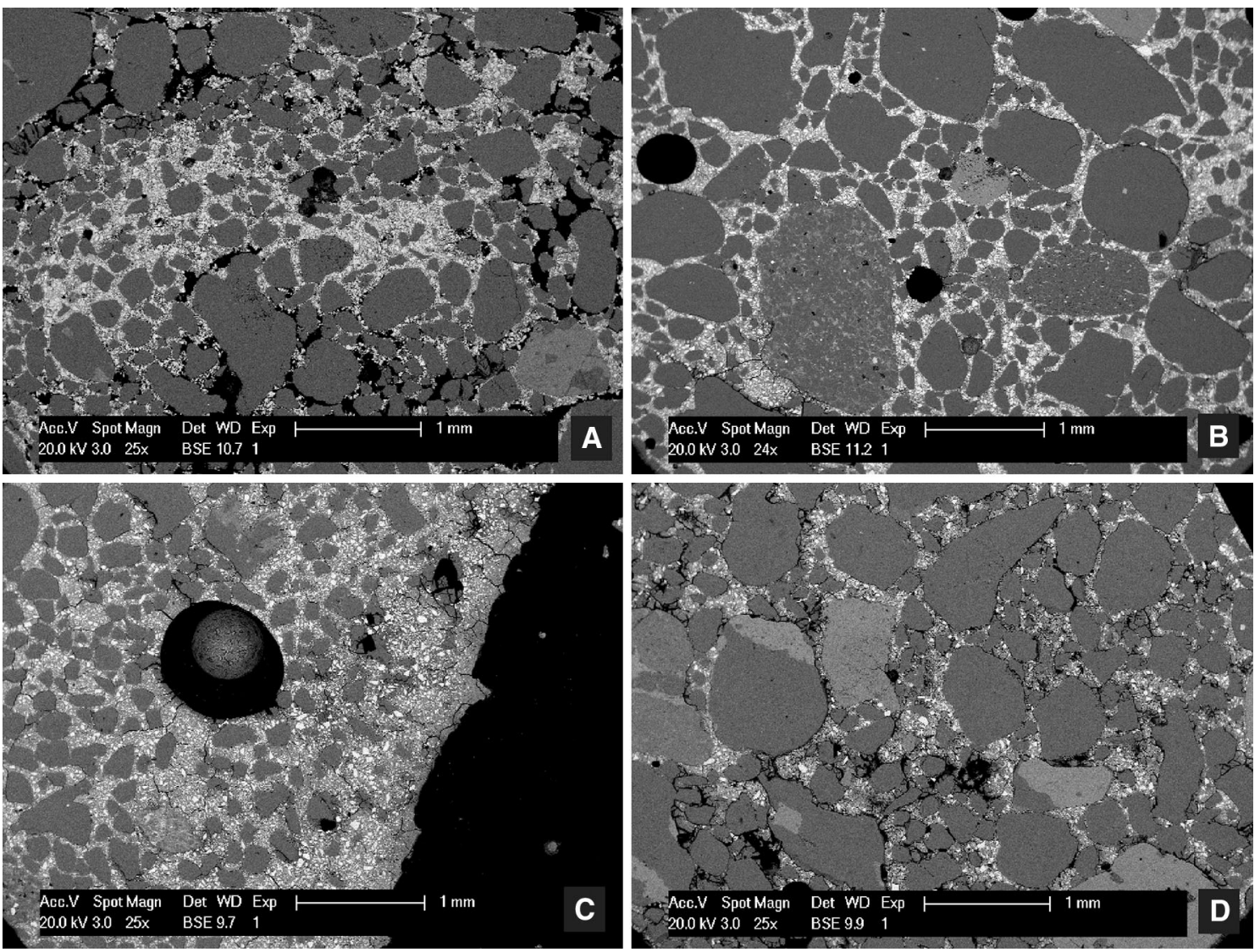

Fig. 4 Packing of sand aggregates. In sample GP1 a, glass aggregates cluster in zones (central in picture) rather than filling in voids between the sand aggregates. In sample GP2 (b), the glass-IP matrix is distributed homogeneously between glass particles. In sample GP3 (c), large differences exist in sand grain size throughout the sample. In

parameters are all increasing towards higher $\mathrm{L} / \mathrm{S}$ ratios. Figure 5 shows representative SEM images of cracks occurring in the different samples. It is difficult to observe cracks at magnifications less than $150 \times$ in sample GP1, because they are less common compared to other samples, smaller in size and because IP matrix formation is limited and porosity is large. However, under SE mode and at high magnification, cracks can be observed (Fig. 5a). In sample GP2, cracks are visible from magnifications $>50 \times$ and become obvious from magnifications $>150 \times$ (Fig. 5b). Most commonly, cracks are perpendicular to glass or aggregate grain boundaries. Cracks at the matrix-glass interphase occur, but much less commonly and are generally connected to cracks perpendicular to the interphase penetrating the matrix. No cracks penetrate through glass or aggregates. Although limited growth of IP aggregates on the crack surface can be observed (Fig. 2b), cracks are not sealed once formed. In sample GP3, cracks are more prominent compared to sample GP2 and can be observed from magnifications $>25 \times$. Especially larger-scale (longer) cracks are more common. These cracks can be considered sample GP4 (d), much less remaining glass aggregates are present, and much less IP matrix has been formed, resulting in a structure composed largely of touching sand aggregates with large interstitial porosity

as individual smaller-scale cracks perpendicular to grain boundaries which have been interconnected through segments along the grain boundary-IP matrix interphase. In sample GP3, a clear relation can also be observed between the ratio of IP matrix to aggregates on the one hand and crack connectivity on the other hand, with longer crack length occurring in regions with less aggregates. This seems logical, as cracks most commonly terminate at aggregate boundaries. In sample GP4, cracks are the largest in size and are even macroscopically visible. On BSE images, it is difficult to distinguish between glass dissolution horizons bordering sand aggregates and cracks, but on SE images a clear cracking pattern can be distinguished (Fig. 5d).

In order to better quantify the porosity of the samples, water absorption and mercury intrusion analyses were performed. The results are shown in Table 10 and Fig. 6. Both analyses indicate that the porosity of GP2 $<$ GP3 $<$ GP4 $<$ GP1.

In Fig. 7, the incremental mercury intrusion curves are shown, in order to be able to inspect which pore and crack 

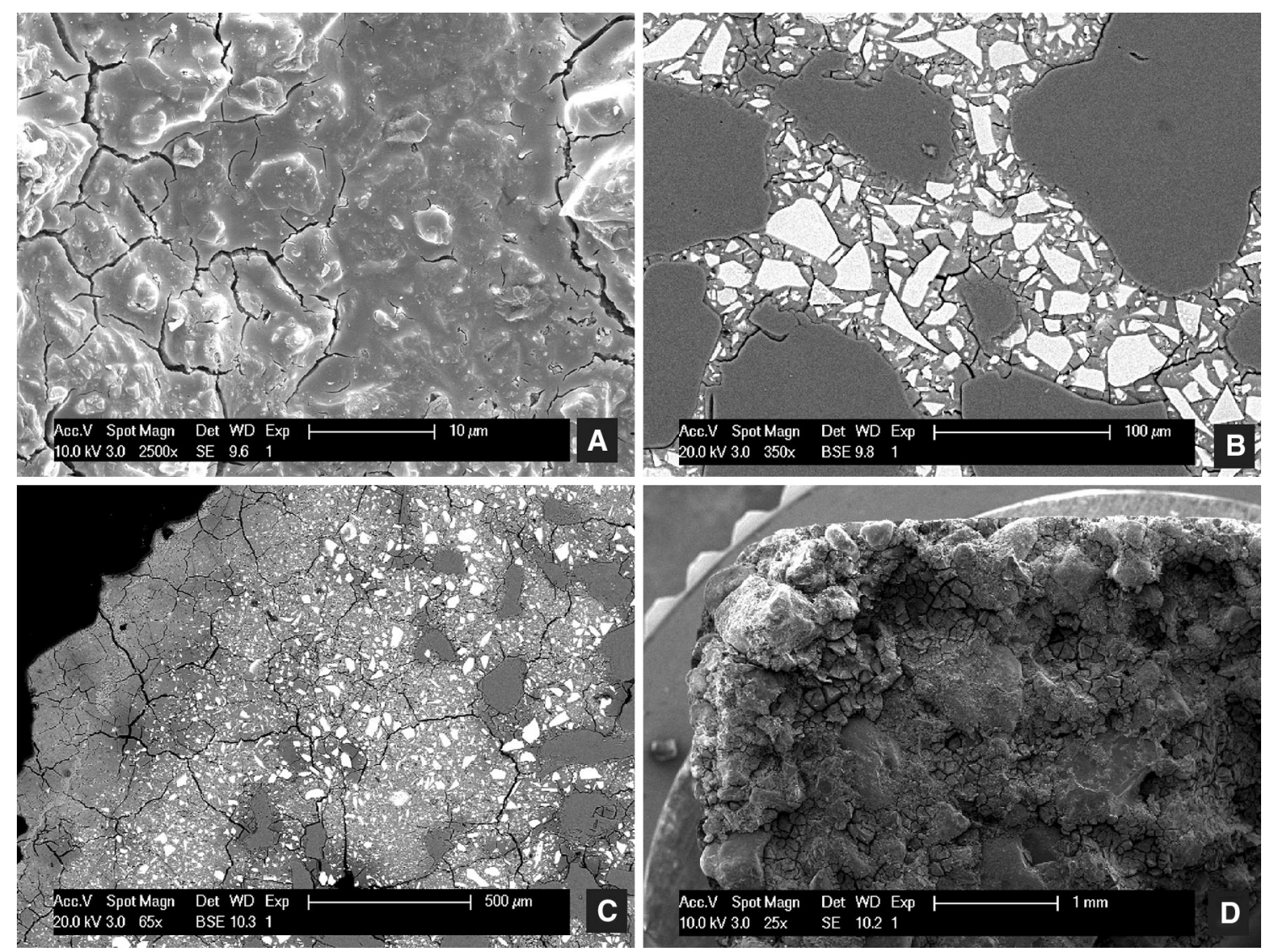

Fig. 5 Shrinkage crack formation. a Sample GP1 with limited cracking only visible at high magnification and on SE images. b Sample GP2 showing shrinkage cracks mostly perpendicular to and terminating at grain boundaries. c Sample GP3 showing more

Table 10 Water absorption: Apparent porosity in \%

\begin{tabular}{llll}
\hline GP1 & GP2 & GP3 & GP4 \\
\hline 18 & 12 & 14 & 17 \\
\hline
\end{tabular}

sizes contribute to the total porosity and how these contributions differ for samples of different $\mathrm{L} / \mathrm{S}$ ratios. Pores $>10 \mu \mathrm{m}$ occur only in sample GP1 and GP4. In sample GP1, these pores should be interpreted as the large pores occurring between sand particles which were observed on the SEM images. In sample GP4, large pores are less common and a prominent peak is present around $10 \mu \mathrm{m}$. These pores represent the dissolution zones between sand grains, where only limited IP matrix was formed. However, cracks could also contribute to porosity in this size range. Most of the porosity of samples GP2, GP3 and GP4 is present in the size range of $10-0.1 \mu \mathrm{m}$. When observing the SEM images, it is obvious that the IP matrix fills the voids between the undissolved glass grains nearly completely in these samples and that thus nearly all porosity in extensive crack formation in zones with less remaining aggregates. d SE image of a fracture surface of sample GP4 with extensive crack formation visible at low magnification

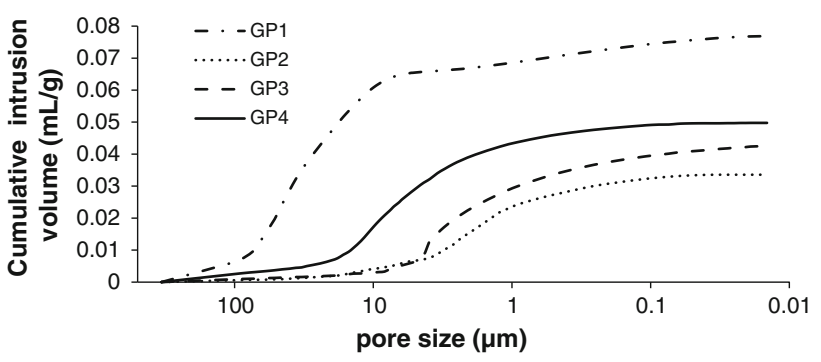

Fig. 6 Cumulative mercury intrusion $(\mathrm{mL} / \mathrm{g})$ versus pore size $(\mu \mathrm{m})$

this size range represents cracks. The asymmetric profiles, visible at the peak around $5 \mu \mathrm{m}$ in samples GP3 and GP4 and at the peak around $2 \mu \mathrm{m}$ in sample GP2, are attributed to the "bottleneck effect", which occurs when mercury is intruded into non-spherical pores, which have a small entrance diameter but a large overall volume [32]. The fact that the maximum peak occurs at a smaller pore size in sample GP2 confirms the observation that cracks are smaller in this sample, while small-scale cracks are connected to form larger scale cracks in samples GP3 and GP4. 

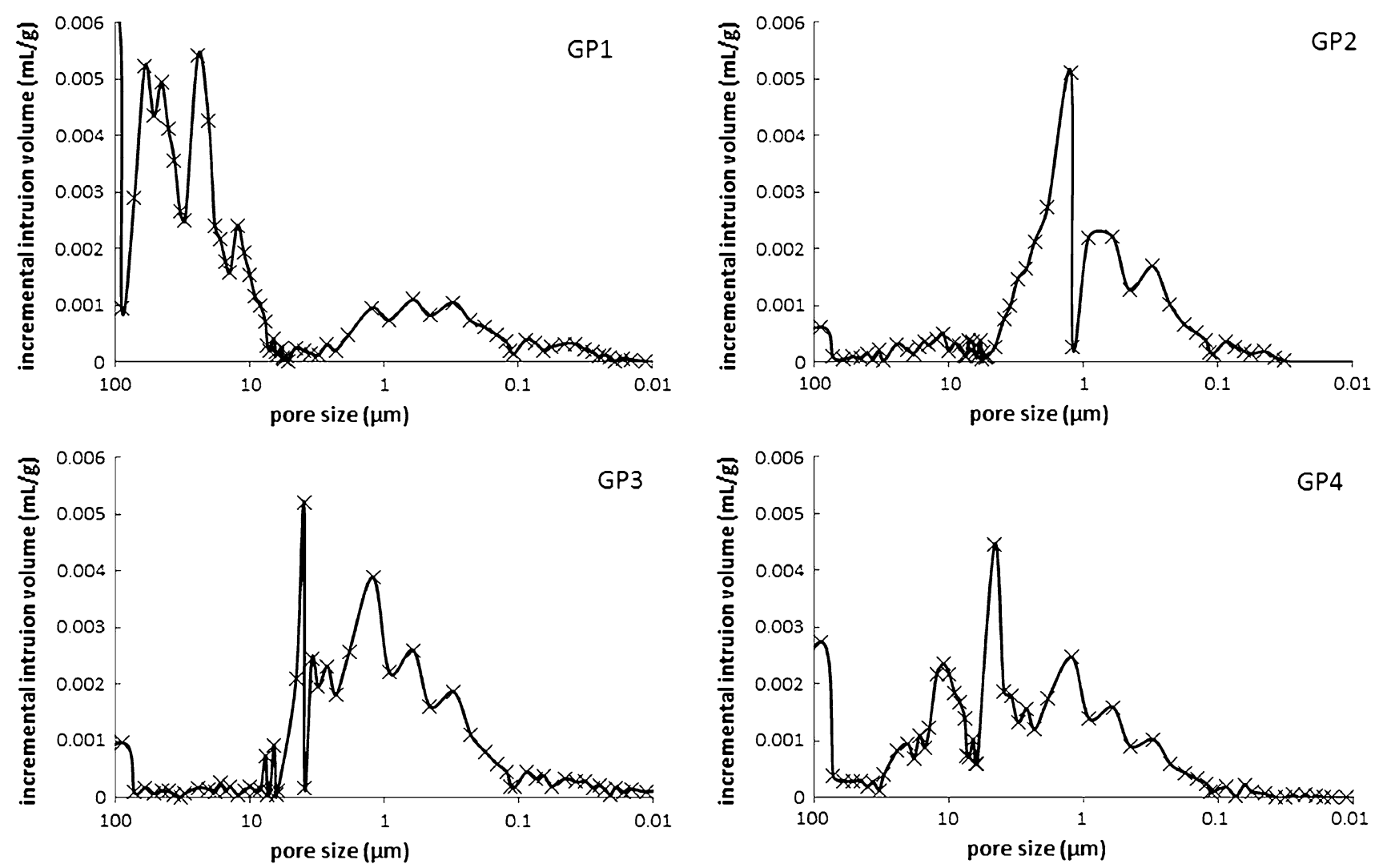

Fig. 7 Incremental pore size distribution curves obtained by mercury intrusion analysis

As the majority of the porosity between 10 and $0.1 \mu \mathrm{m}$ is attributed to cracks, the cumulative volume of mercury intruded between 10 and $0.1 \mu \mathrm{m}$ gives an indication of the total volume of cracks in the samples. The following volumes are obtained (in mL/g): GP1: 0.013; GP2: 0.028; GP3: 0.036; GP4: 0.031. An overall increase in intruded volume can thus be observed from sample GP1 to GP3. As in sample GP4 cracks larger than $40 \mu \mathrm{m}$ can be clearly observed (Fig. 5d), the pore population between 10 and $40 \mu \mathrm{m}$ can also be included and in this case the intruded volume increases to $0.045 \mathrm{~mL} / \mathrm{g}$. The increase in total volume of cracks thus confirms the more extensive crack formation towards higher L/S ratios observed in the SEM images.

\section{Microchemistry}

The IP microchemistry of the major elements ( $\mathrm{Na}, \mathrm{K}, \mathrm{Si}$, $\mathrm{Al}, \mathrm{Fe}, \mathrm{Ca}$ ), determined by EPMA analysis, is summarised in Fig. 8. For each element, the average and median values and ranges are given, determined by analysing different points at different locations throughout the samples. When looking at the average values, a first important observation is that the average Na content is similar in samples GP2-34. Apparently the tripling of the Na content of the mixtures, as was indicated in Table 2, did not lead to a higher average $\mathrm{Na}$ content in the IP phase. In sample GP1, the average $\mathrm{Na}$ content is higher compared to the other samples. For K, a similar trend as for $\mathrm{Na}$ can be observed, with similar average $\mathrm{K}$ contents occurring in samples GP2, GP3 and GP4 and a higher content in GP1. For Si, the average content is similar in the different samples, although a slightly decreasing trend could be noted from sample GP2 to GP4. This decreasing trend is more pronounced for Al. For $\mathrm{Ca}$ and $\mathrm{Fe}$, an opposite trend occurs, with increasing content towards higher $\mathrm{L} / \mathrm{S}$ ratios. In the case of $\mathrm{Fe}$, this does not hold true for sample GP4, which has a slightly lower Fe content compared to sample GP3, due to the presence of analyses with very low Fe content. When looking at the standard deviation of the element content, it can be observed that for all elements the deviation increases when going from sample GP2 to GP4, although for some elements this is less pronounced than for others. This means that at higher L/S ratios, a larger range of IP compositions is formed, while for lower L/S ratios, the composition is more homogeneous.

EPMA-WDS element maps of $\mathrm{Na}, \mathrm{Si}, \mathrm{Al}, \mathrm{Fe}$ and $\mathrm{Ca}$ in GP2 and GP4 are shown in Fig. 9. The grain boundaries of undissolved glass particles are indicated in red on the maps, while cracks are indicated in yellow. It can be observed that 

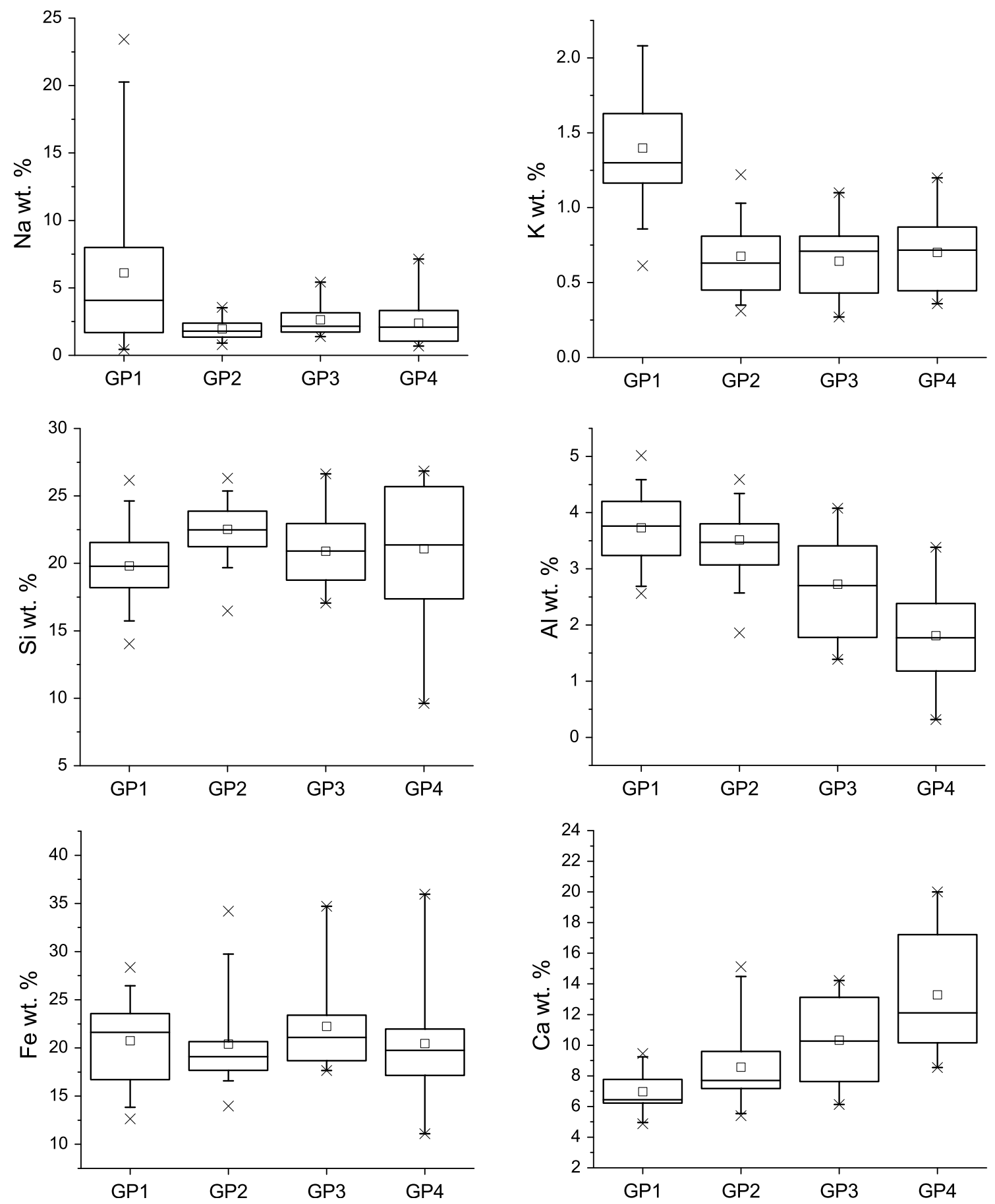

Fig. 8 Boxplots comparing the variation in microchemistry of the major elements of the IP phase in samples of different L/S. x: minimum and maximum values; vertical line: percentile 95; box: percentile 75, horizontal line: median, square: mean

$\mathrm{Na}$ concentrations vary within the IP matrix, with larger differences in concentration occurring in GP4 compared to GP2. In GP2, the Si content is similar in the glass and the IP matrix, while in GP4 Si content of the IP is similar as the glass near the grains, while it decreases further from the grains. The $\mathrm{Al}$ and $\mathrm{Fe}$ contents are higher in the grains compared to the IP matrix, with the difference being more pronounced in GP4. Ca typically occurs in concentrated zones in the matrix, where it is present in higher concentration than in the glass. A remarkable observation is the apparent occurrence of cracks at the edges of zones of higher $\mathrm{Na}$ of $\mathrm{Ca}$ concentration, which can be observed best in GP4 (maps of $\mathrm{Na}$ and $\mathrm{Ca}$ ), where differences in $\mathrm{Ca}$ and $\mathrm{Na}$ concentration throughout the IP are higher. 


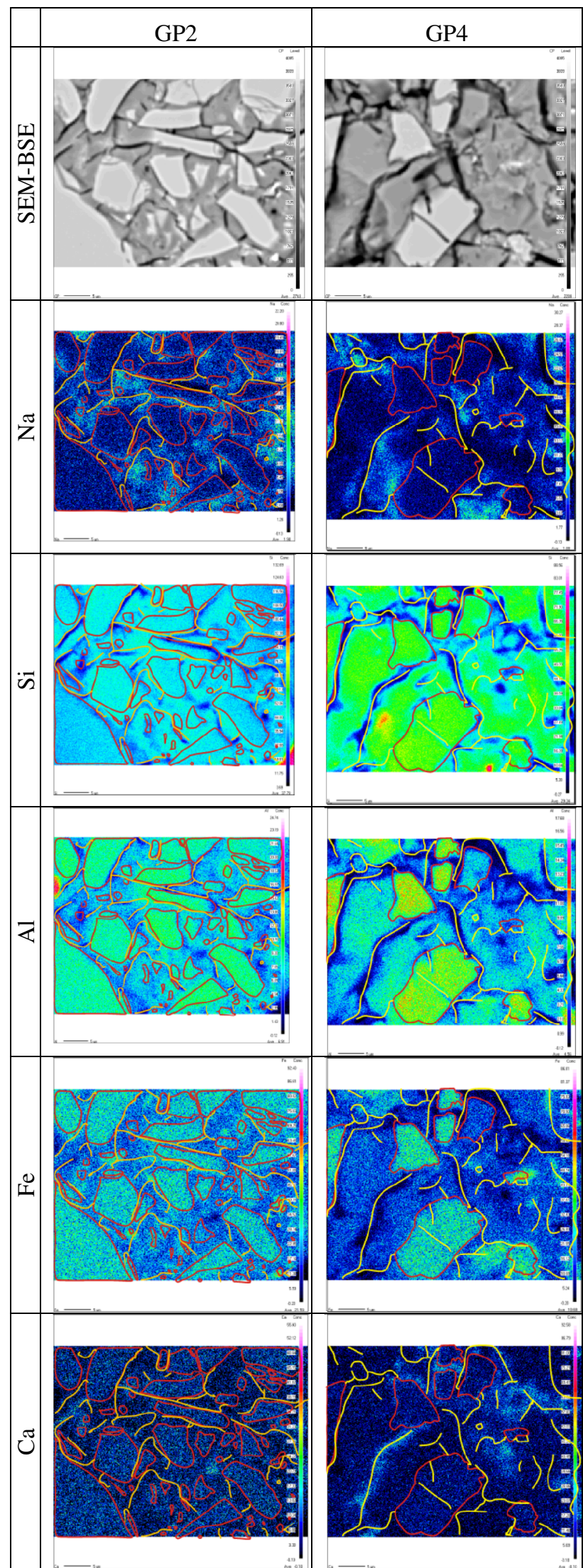

4Fig. 9 WDS mapping of samples GP2 and GP4. The upper two images are SEM-BSE images, while the other images represent EPMA-WDS maps of $\mathrm{Na}, \mathrm{Si}, \mathrm{Al}, \mathrm{Fe}$ and $\mathrm{Ca}$. In the maps the grain boundaries of the undissolved grains are indicated (red) as well as cracks (yellow). Concentrations given in the legend are indicative

In Table 11 the average IP composition determined by EPMA analysis is compared with the mixture composition, which was given in Table 2 . When looking at the ratio of the average IP composition to the mixture composition (ratio GP/mix, Table 11), some clear trends can be observed. When assessing the $\mathrm{Na}$ content, the average values of all spot analyses indicate an opposite trend, meaning that the higher the $\mathrm{Na}$ content of the mix, the lower the average Na content in the IP. This indicates that a large amount of $\mathrm{Na}$ is either accommodated in another phase apart from the IP phase, or that high variations exist between different parts of the sample. When comparing the average IP composition with the mixture composition, it can also be seen that $\mathrm{Al}$ is depleted in the IP towards higher $\mathrm{L} / \mathrm{S}$ ratios and that $\mathrm{Ca}$ and $\mathrm{Fe}$ are enriched towards higher $\mathrm{L} / \mathrm{S}$ ratios.

\section{Discussion}

The results of this paper indicate the possibility of inorganic polymer (IP) synthesis from Fe-silicate glasses containing only low amounts of Al. Additionally, the optimum amount of activating solution to be used for obtaining the best inorganic polymer properties was indicated. Other authors have indicated that increasing $\mathrm{NaOH}$ and $\mathrm{Na}$-silicate contents improves IP properties only until a certain extent and that more addition results in a decrease in material properties, such as compressive strength. This has been observed for aluminosilicate IP [1, 33], but also for inorganic polymers derived from non-ferrous slags [7]. In this work, it was observed that when lowering the activating solution/glass ratio $\mathrm{L} / \mathrm{S}$ ratio down to a certain extend, an increase in compressive strength, a more optimal binder/aggregate ratio, a better particle packing and a reduction in porosity and shrinkage cracks was obtained. Additionally, upon water immersion, less $\mathrm{Na}$ was released in solution and a lower water $\mathrm{pH}$ was obtained.

When looking at the microstructure of samples of differing $\mathrm{L} / \mathrm{S}$ ratios, the origin of their differing properties can be explained. One of the most striking differences between the samples is the differing degree of glass dissolution, with a higher degree of dissolution occurring towards higher $\mathrm{L} / \mathrm{S}$ ratios. The activating solution composition used was identical for the different $\mathrm{L} / \mathrm{S}$ ratios and the initial $\mathrm{pH}$ and dissolution kinetics are thus expected to be similar. However, it can be understood that when more activating 
Table 11 Calculated vs. measured aver IP composition (wt \%)

\begin{tabular}{|c|c|c|c|c|c|c|c|c|c|c|c|c|}
\hline \multirow[t]{2}{*}{ (wt \%) } & \multicolumn{3}{|l|}{ GP1 } & \multicolumn{3}{|l|}{ GP2 } & \multicolumn{3}{|l|}{ GP3 } & \multicolumn{3}{|l|}{ GP4 } \\
\hline & Mix & GP & Ratio & Mix & GP & Ratio & Mix & GP & Ratio & Mix & GP & Ratio \\
\hline $\mathrm{Si}$ & 18.5 & 17.8 & 1.0 & 18.6 & 22.9 & 1.2 & 18.7 & 20.9 & 1.1 & 19 & 21.1 & 1.1 \\
\hline $\mathrm{Na}$ & 3.5 & 15.4 & 4.4 & 4.8 & 3.8 & 0.8 & 6.1 & 2.6 & 0.4 & 9.0 & 2.4 & 0.3 \\
\hline $\mathrm{Al}$ & 4.2 & 2.8 & 0.7 & 4.1 & 3.3 & 0.8 & 3.9 & 2.7 & 0.7 & 3.6 & 1.8 & 0.5 \\
\hline $\mathrm{Ca}$ & 9.4 & 7.6 & 0.8 & 9.0 & 8.0 & 0.9 & 8.7 & 10.3 & 1.2 & 7.9 & 13.3 & 1.7 \\
\hline $\mathrm{Fe}$ & 24.7 & 15.7 & 0.6 & 23.8 & 19 & 0.8 & 22.9 & 22.3 & 1.0 & 20.9 & 20.4 & 1.0 \\
\hline K & 1.0 & 1.2 & 1.2 & 0.9 & 0.6 & 0.7 & 0.9 & 0.9 & 1.0 & 0.8 & 1.0 & 1.3 \\
\hline $\mathrm{Mg}$ & 1.0 & 0.9 & 0.9 & 1.0 & 0.9 & 0.9 & 0.9 & 0.6 & 0.7 & 0.8 & 0.7 & 0.9 \\
\hline
\end{tabular}

Mix: mixture composition (glass + activating solution—water free); GP: average IP composition determined by EPMA analysis; ratio: ratio of GP to mix

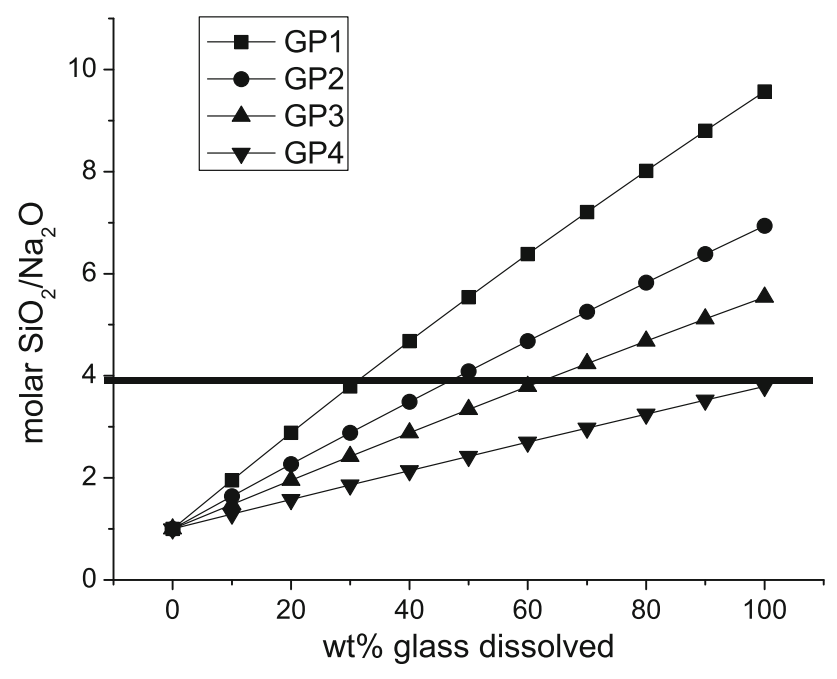

Fig. 10 Bulk $\mathrm{SiO}_{2} / \mathrm{Na}_{2} \mathrm{O}$ ratio in solution at progressive glass dissolution. Assumption is for congruent and complete glass dissolution. The horizontal line is given as an example: to reach a molar $\mathrm{SiO}_{2} / \mathrm{Na}_{2} \mathrm{O}$ ratio of $4,30,50,60$ and 100 wt $\%$ of glass has to be dissolved in samples GP1, GP2, GP3 and GP4 respectively

solution is added, a higher amount of glass can be dissolved. The reason for this is that for a given $\mathrm{pH}$ and $\mathrm{Na}$ content, IP gel formation will only occur when a certain concentration of dissolved constituents is reached in solution [33-36]. The more activating solution is added, the more glass has to be dissolved to alter the solution composition to such an extent that gelation of the solution occurs [37].

To illustrate the differing evolution of solution compositions when varying amounts of activating solution are used, the evolution of the $\mathrm{SiO}_{2} / \mathrm{Na}_{2} \mathrm{O}$ molar ratio of mixtures of varying $\mathrm{L} / \mathrm{S}$ ratio with progressive glass dissolution is shown in Fig. 10. Initially, when no glass is dissolved, the $\mathrm{SiO}_{2} / \mathrm{Na}_{2} \mathrm{O}$ molar ratio in solution corresponds to the $\mathrm{SiO}_{2} / \mathrm{Na}_{2} \mathrm{O}$ molar ratio of the activating solution-which is
1.00 in this case-and is the same in all mixtures. At this $\mathrm{SiO}_{2} / \mathrm{Na}_{2} \mathrm{O}$ ratio, dissolved silicates will be nearly completely depolymerised and thus occur as monomers. When glass is progressively dissolved, more $\mathrm{Si}$ will be liberated and the $\mathrm{Si}$ concentration and thus the molar ratio of $\mathrm{SiO}_{2} /$ $\mathrm{Na}_{2} \mathrm{O}$ will increase and progressive $\mathrm{Si}$ polymerisation will occur. As an example, a horizontal line is drawn at a $\mathrm{SiO}_{2} /$ $\mathrm{Na}_{2} \mathrm{O}$ molar ratio of four. To reach this molar ratio in solution, 30, 50, 60 and $100 \mathrm{wt} \%$ of glass have to be dissolved in mixtures of $\mathrm{SiO}_{2} / \mathrm{Na}_{2} \mathrm{O}$ ratios of 0.3 (GP1), 0.45 (GP2), 0.6 (GP3) and 1.0 (GP4) respectively.

This thus confirms that for identical activating solution compositions, the amount of glass which needs to be dissolved to provide sufficient $\mathrm{Si}$ in solution for extensive polymerisation and gelation to occur is reached faster in mixtures with lower contents of activating solution. In sample GP1, fast gelation could be responsible for the clustering and alignment of glass aggregates around sand aggregates during mixing. Sample GP4 represents the other extreme, as nearly all glass was dissolved and the sample hardened only slowly, after an extensive drying period. The saturated liquid, containing the majority of dissolved constituents was expulsed, either by bleeding, occurring closely after sample preparation, or during drying of the sample. This resulted in only limited IP formation in the centre of the sample and more extensive IP formation on the outer part of the sample. In sample GP2, gelation probably also occurred already during the mixing. In SEM images of the samples it can be observed that only the smallest glass particles and the rim of larger glass particles are dissolved. Gelation during the mixing resulted in a much lower fluidity of the mixture and prevented segregation of sand grains during the tapping of the material after moulding. At higher L/S ratios, gelation occurs only after moulding of the sample. However, when glass is milled finer and mechanically mixed, a sudden decrease in fluidity of the mixture after a few minutes of mixing indicates that also at these higher $\mathrm{L} / \mathrm{S}$ ratios gelation can be 
obtained during the mixing already [30]. When a larger grain size is used and when mixed less extensively, as done in this paper, gelation occurs only after moulding. This is evidenced by the extensive segregation occurring during tapping of sample GP3, which is not possible in a highly viscous gelated sample, such as GP2.

An important observation is the differing degree of shrinkage cracking occurring in the samples, with shrinkage cracks being larger and more interconnected towards higher L/S ratios. Shrinkage of gels is attributed to contraction of the network occurring when progressive polymerisation occurs, resulting in expulsion of water from the gel [38]. At a certain point, the IP structure has obtained certain rigidity, due to polymerisation and compaction of the structure and further shrinkage is prevented [38]. Shrinkage doesn't necessarily lead to cracking, unless it is heterogeneous through the sample. Heterogeneous shrinkage can occur e.g. when drying is fast combined with a low permeability.

In the current work it was indicated that a higher IP/ aggregate ratio leads to more extensive development of shrinkage cracks. Microstructural investigation indicates that aggregates play a role in reducing shrinkage of IP mortars. This has already been indicated by other authors [41, 42]. As less glass is dissolved when less activating solution is added, more glass aggregates remain and less IP matrix is formed and extensive development of cracks is inhibited. However, this cannot be the only factor determining crack development as the highest amount of cracking occurs in sample GP4, in which IP formation in the core of the sample was limited.

An additional factor influencing shrinkage is the IP chemistry, as indicated by Keunzel et al. [39], who reported a linear relation between $\mathrm{Na}$ content of metakaolin based IP mixtures and shrinkage development. The authors attributed more extensive shrinkage to a larger amount of "structural water" needed in the samples when higher contents of $\mathrm{Na}$ are present. According to the authors, shrinkage is initiated when this structural water is removed during drying. However, EPMA analyses performed in this work indicate that the Na content in the IP phase formed at varying $\mathrm{L} / \mathrm{S}$ ratio is quite similar. Nevertheless, it is known that the nanostructure of aluminosilicate gels prepared from mixtures of high $\mathrm{Na} / \mathrm{Si}$ ratios tends to be more compact and less porous than gels prepared from mixtures of lower $\mathrm{Na} / \mathrm{Si}$ ratios [14, 40]. Reduction of gel permeability would lead to higher capillary pressures gradients during drying and make gels more subjective to cracking.

Another parameter of influence could be the local variation in IP chemistry. Indeed, samples with larger chemical heterogeneity (GP4) seem to have more developed shrinkage cracking. From the element mappings it is apparent that cracks are aligned along zones of higher $\mathrm{Na}$ or $\mathrm{Ca}$ content or form at the edges between zones of higher and lower $\mathrm{Na}$ or $\mathrm{Ca}$ content. IP zones of differing cation content would have differing contents of structural water, in general higher water contents occur in zones with higher cation contents. In this case, shrinkage would thus differ in distinct zones, as different amounts of water incorporated in the structure would lead to a differing phase density and a differing volumetric change during curing. This would lead to stresses that can induce cracking. The optimal L/S obtained in this paper was 0.45 , and although compressive strengths similar to OPC-based mortars could be produced, shrinkage cracks are still common and it is clear that further optimisation is needed. In this work an activating solution of molar $\mathrm{SiO}_{2} / \mathrm{Na}_{2} \mathrm{O}$ ratio 1.0 was used, but this ratio can be further optimized. For aluminosilicate IP mixtures, $\mathrm{SiO}_{2} / \mathrm{Na}_{2} \mathrm{O}$ ratios ranging from 0 to 3.4 are reported, but different authors indicate optimal properties in the area of 1.4-1.6. [1, 43]. A more detailed study of the nanostructure and porosity of Fe-silicate IP prepared with varying $\mathrm{L} / \mathrm{S}$ ratios will therefore be presented in a later work.

\section{Conclusions}

This paper shows the potential for the use of Fe-silicate glasses as an alternative raw material for the synthesis of inorganic polymer (IP) cements. It was shown that IP monoliths could be produced by activating solution $/ \mathrm{Fe}$ silicate glass ratios (L/S) of 0.3-1.0. All these IP monoliths were insoluble in water, although a considerable amount of residual $\mathrm{Na}$ was released towards a higher $\mathrm{L} / \mathrm{S}$ ratio. It was also indicated that increasing the activating solution content does not necessarily lead to better properties. For the activating solution composition (in wt $\% \mathrm{Na}_{2} \mathrm{O}: 15 ; \mathrm{SiO}_{2}$ : $\left.13 ; \mathrm{H}_{2} \mathrm{O}: 72\right)$ and $\mathrm{L} / \mathrm{S}$ ratios studied $(0.3,0.45,0.6,1.0)$, the composition of 0.45 was considered optimal, while compositions of lower and higher L/S ratios resulted in lower compressive strength and a larger amount of excessive $\mathrm{Na}$, a higher residual $\mathrm{pH}$ and a higher porosity. These differing properties are explained by the lower amount of glass dissolution required to reach sufficient silica saturation and IP gel formation when lower amounts of activating solution are used. This leads to a more homogenous IP composition, more rich in $\mathrm{Al}$ but containing less $\mathrm{Fe}, \mathrm{Mg}, \mathrm{Ca}$. Additionally, when less glass is dissolved, less IP matrix is formed, which results in a dense packing of glass and aggregates, bound by the inorganic polymer matrix, in which connectivity of micro-cracks is inhibited. At an activating solution to glass ratio of 0.45 , inorganic polymer cement with compressive strength similar to OPC 52.5 could be produced. At this L/S ratio, only $10 \mathrm{wt} \%$ of Nasilicate is required in the powder mix and as Fe-silicate 
glass can be obtained as a residue from various industrial processes, the production of Fe-silicate IP cement becomes both economically and ecologically interesting.

Acknowledgments We gratefully acknowledge the Agentschap voor Innovatie door Wetenschap en Technologie (IWT) and Group Machiels for financial support (project IWT100517), Pieter Lhoëst and Annelies Malfliet for the EPMA measurements, Gerda Hechtermans for the mercury intrusion porosimetry measurements and the Hercules Foundation (project ZW09-09) for funding the EPMA equipment. YP is thankful to the Research Foundation-Flanders for the post-doctoral fellowship.

\section{References}

1. Davidovits, J.: Geopolymer Chemistry \& Applications, 3rd edn. Institut Géopolymère, Saint-Quentin (2011)

2. van Deventer, J.S.J., Provis, J.L., Duxson, P., Brice, D.G.: Chemical Research and Climate Change as Drivers in the Commercial Adoption of Alkali Activated Materials. Waste Biomass Valoriz 1(1), 145-155 (2010)

3. Lemougna, P.N., MacKenzie, K.J.D., Jameson, G.N.L., Rahier, H.: Chinje Melo U.F.: the role of iron in the formation of inorganic polymers (geopolymers) from volcanic ash: a ${ }^{57} \mathrm{Fe}$ Mössbauer spectroscopy study. J Mater Sci 48, 5280-5286 (2013)

4. Pontikes, Y., Machiels, L., Onisei, S., Pandelaers, L., Geysen, D., Jones, P., Blanpain, B.: Slags with a high $\mathrm{Al}$ and $\mathrm{Fe}$ content as precursors for inorganic polymers. Appl. Clay Sci. 73, 93-102 (2013)

5. Onisei, S., Pontikes, Y., Van Gerven, T., Angelopoulos, G., Velea, T., Predica, V., Moldovan, P.: Synthesis of organic polymers using fly ash and primary lead slag. J. Hazard. Mater. 205-206, 101-110 (2012)

6. Komnitsas, K., Zaharaki, D., Perdikatsis, V.: Geopolymerisation of low calcium ferronickel slags. J. Mater. Sci. 42(9), 3073-3082 (2007)

7. Komnitsas, K., Zaharaki, D., Perdikatsis, V.: Effect of synthesis parameters on the compressive strength of low-calcium ferronickel slag inorganic polymers. J. Hazard Mater. 161, 760-768 (2009)

8. Maragkos, I., Giannopoulou, I.P., Panias, D.: Synthesis of ferronickel slag-based geopolymers. Min. Eng. 22(2), 196-203 (2009)

9. Zaharaki, D., Komnitsas, K., Perdikatsis, V.: Use of analytical techniques for identification of inorganic polymer gel composition. J. Mater. Sci. 45, 2715-2724 (2010)

10. Pontikes, Y., Onisei, S., Machiels, L., Jones, P. T., Blanpain, B.: On the use of secondary copper production fayalitic slag in applications of higher added-value Leuven, Centre for High Temperature Processes and Sustainable Materials Management, Department of Metallurgy and Materials Engineering, KU Leuven, internal report (2011)

11. Bosmans, A., Vanderreydt, I., Geysen, D., Helsen, L.: The crucial role of Waste to-Energy technologies in enhanced landfill mining: a technology review. J. Clean. Prod. 55, 10-23 (2012)

12. Jones, P.T., Geysen, D., Tielemans, Y., Van Passel, S., Pontikes, Y., Blanpain, B., Quaghebeur, M., Hoekstra, N.: Enhanced landfill mining in view of multiple resource recovery: a critical review. J. Clean. Prod. 55, 45-55 (2012)

13. Davidovits, J.: Properties of Geopolymer Cements. In: Proceedings of the 1st International Conference on Alkaline Cements and Concretes, pp. 131-149 (1994)
14. Provis, L.J., van Deventer, J.S.J.: Geopolymers: Structures, Processing, Properties and Industrial Applications, Woodhead Publishing Ltd (2009)

15. Dimas, D., Giannopoulou, I., Panias, D.: Polymerization in sodium silicate solutions: a fundamental process in geopolymerization technology. J. Mater. Sci. 44, 3719-3730 (2009)

16. Giannopoulou, I., Panias, D.: Hydrolytic stability of sodium silicate gels in the presence of aluminium. J. Mater. Sci. 45, 5370-5377 (2010)

17. Rietveld, H.M.: A method for including the line profiles of neutron powder diffraction peaks in the determination of crystal structures. Acta Crystallogr. 21, A228 (1966)

18. Rietveld, H.M.: A profile refinement method for nuclear and magnetic structures. J. Appl. Crystallogr. 2, 65-71 (1969)

19. Coelho, A. A.: TOPAS-Academic; A Computer Programme for Rietveld Analysis. http://www.topas-academic.net/. Accessed 31 Aug 2013

20. Cheary, R.W., Coelho, A.A.: A fundamental parameters approach of X-ray line-profile fitting. J. Appl. Crystallogr. 25, 109-121 (1992)

21. European Committee for Standardization: EN 196-1, Methods of testing cement-Part 1: Determination of strength (1994)

22. Elkem: Elkem Materials Mixture Analyzer software. http://www. elkem.com/en/silicon-materials/support/software-emma/. Last accessed 31 Aug 2013

23. Barbosa, V.F.F., MacKenzie, K.J.D., Thaumaturgo, C.: Synthesis and characterisation of materials based on inorganic polymers of alumina and silica: sodium polysialate polymers. Int. J. Inorg. Mater. 2, 309-331 (2000)

24. Davidovits, J.: Chemistry of geopolymeric system, terminology. In Geopolymer'99 Proceedings, Saint-Quentin, France (1999)

25. International Organization for standardization: ISO 10545-3. Ceramic tiles-Part 3: Determination of water absorption, apparent porosity, apparent relative density and bulk density (1994)

26. Lee, W.K.W., van Deventer, J.S.J.: Structural reorganisation of class F fly ash in alkaline silicate solutions. Colloids Surf. A 211(1), 49-66 (2002)

27. Criado, M., Fernández-Jiménez, A., Palomo, A.: Alkali activation of fly ash: effect of the $\mathrm{SiO}_{2} / \mathrm{Na}_{2} \mathrm{O}$ ratio: Part I: FTIR study. Microporous Mesoporous Mater. 106(1-3), 180-191 (2007)

28. Rees, C.A., Provis, J.L., Lukey, G.C., van Deventer, J.S.J.: Attenuated total reflectance fourier transform infrared analysis of fly ash geopolymer gel aging. Langmuir 23(15), 8170-8179 (2007)

29. Sweet, J.R., White, W.B.: Study of sodium silicate glasses and liquids by infrared spectroscopy. Phys. Chem. Glasses 10, 246-251 (1969)

30. Machiels, L., Arnout, L., Jones, P.T., Blanpain, B., Pontikes, Y.: $\mathrm{Fe}-\mathrm{Si}$-glasses as geopolymer precursors: decreasing the amount of activating solution? In: Proceedings of the 3th slag Valorisation Symposium. KU Leuven, Belgium, pp. 303-306 (2013)

31. Kriven, W.M., Bell, J.L., Gordon, M.: Microstructure and microchemistry of of fully-reacted geopolymers and geopolymer matrix composites. Ceram. Trans. 153, 227-250 (2003)

32. Moro, F., Böhni, H.: Ink-bottle effect in mercury intrusion porosimetry of cement-based materials. J. Colloid Interface Sci. 246(1), 135-149 (2001)

33. Duxson, P., Mallicoat, S.W., Lukey, G.C., Kriven, W.M., van Deventer, J.S.J.: The effect of alkali and $\mathrm{Si} / \mathrm{Al}$ ratio on the development of mechanical properties of metakaolin-based geopolymers. Colloids Surf A 292(1), 8-20 (2007)

34. Glukhovsky, V.D.: Soil silicates. Gosstroyizdat, Kiev, 154 p. (1959) 
35. Čejka, J., Corma, A., Zones, S.: Zeolites and Catalysis: Synthesis, Reactions and Applications. vol. 2, 882 p. Wiley-VCH, Weinheim (2010)

36. Rees, C.A.: Mechanisms and kinetics of gel formation in geopolymers. Phd thesis. University of Melbourne, 176p. (2007)

37. Duxson, P., Fernández-Jiménez, A., Provis, J.L., Lukey, G.C., Palomo, A., van Deventer, J.S.J.: Geopolymer technology: the current state of the art. J. Mater. Sci. 42(9), 2917-2933 (2007)

38. Scherer, G.W.: Structure and properties of gels. Cem. Concr. Res. 29, 1149-1157 (1999)

39. Keunzel, C., Vandeperre, L.J., Donatello, S., Boccaccini, A.R., Cheeseman, C.: Ambient temperature drying shrinkage and cracking in metakaolin-based geopolymers. J. Am. Ceram. Soc. 95(10), 3270-3277 (2012)
40. Park, J., Han, Y., Kim, H.: Formation of mesoporous materials from silica dissolved in various $\mathrm{NaOH}$ concentrations: effect of $\mathrm{pH}$ and ionic strength. J. Nanomater. Article ID 528174, 10 pages (2012)

41. Isabella, C., Lukey, G.C., Xu, Hua, van Deventer, J.: The effect of aggregate particle size on formation of geopolymeric gel. In: Proceedings of the Engineering Conferences International. Advanced Materials for Construction of Bridges, Buildings and Other Structures III, Art. 9. ECI digital archives (2005)

42. Steinerova, M.: Mechanical properties of geopolymer mortars in relation to their porous structure. Ceram. Silikáty. 55(4), 362-372 (2011)

43. Sindhunata, van Deventer, J.S.J., Lukey, G.C., Xu, H.: Effect of curing temperature and silicate concentration on fly-ash-based geopolymerisation. Ind. Chem. Res. (45), 3559-3568 (2006) 